ANL-6497

Chemistry

(TID-4500, 17th Ed.)

AEC Research and

Development Report

ARGONNE NATIONAL LABORATORY

9700 South Cass Avenue

Argonne, Illinois

SPECIFIC HEAT DATA ANALYSIS PROGRAM

FOR THE IBM 704 DIGITAL COMPUTER

by

Pat R. Roach

Solid State Science Division

January 1962

Operated by The University of Chicago

under

Contract W-31-109-eng-38 


\section{DISCLAIMER}

This report was prepared as an account of work sponsored by an agency of the United States Government. Neither the United States Government nor any agency Thereof, nor any of their employees, makes any warranty, express or implied, or assumes any legal liability or responsibility for the accuracy, completeness, or usefulness of any information, apparatus, product, or process disclosed, or represents that its use would not infringe privately owned rights. Reference herein to any specific commercial product, process, or service by trade name, trademark, manufacturer, or otherwise does not necessarily constitute or imply its endorsement, recommendation, or favoring by the United States Government or any agency thereof. The views and opinions of authors expressed herein do not necessarily state or reflect those of the United States Government or any agency thereof. 


\section{DISCLAIMER}

Portions of this document may be illegible in electronic image products. Images are produced from the best available original document. 
TABLE OF CONTENTS

Page

I. PURPOSE......................... 3

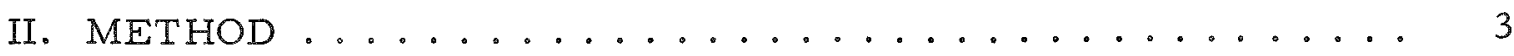

III. OPERATION ..................... 5

A. Specific Heat Calculation Program ............ 5

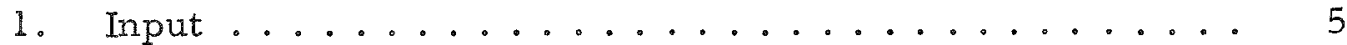

2. Machine Operation ................. 9

3. Output ........................ 10

B. Curvature Correction Program............... 11

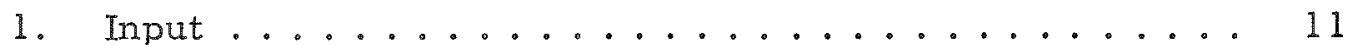

2. Machine Operation ............... 12

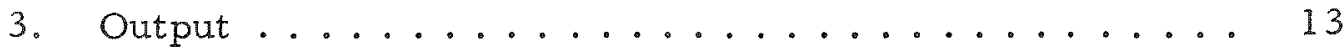

C. Point Plotter.......................... 13

1. Operating Instructions............... 14

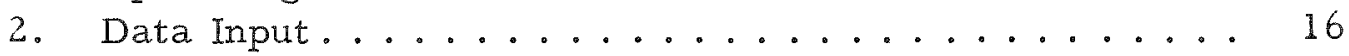

IV. PROGRAM DETAILS. ................ 16

A. Magnetic Thermometer Calculation............ 16

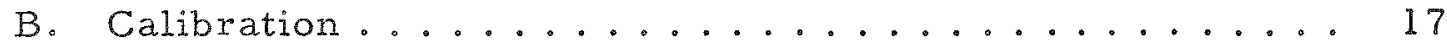

C. Specific Heat Analysis.................. 18

D. Curvature Correction ................... 19

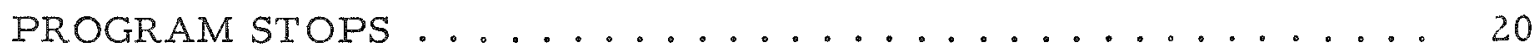

PROGRAM LISTING ....................... 21

FIGURE

No.

Title

Page

1. Fore- and after-drifts of a typical heat capacity point......4 4 


\title{
SPECIFIC HEAT DATA ANALYSIS PROGRAM FOR THE IBM 704 DIGITAL COMPUTER
}

\author{
by
}

Pat R. Roach

\section{PURPOSE}

The purpose of the program described herein is to calculate the specific heat of a substance in the temperature range from 0.3 to $4.2^{\circ} \mathrm{K}$, given temperature calibration data for a carbon resistance thermometer, and given experimental temperature drift and heating period data. The specific heats calculated from these data are then fitted by a curve by the method of least squares and the specific heats are corrected for the effect of the curvature of the data.

\section{METHOD}

The experiment* for which this program was designed is one in which a $\mathrm{He}^{3}$ cryostat is used in order to achieve temperatures in the neighborhood of $0.3^{\circ} \mathrm{K}$ by pumping on $\mathrm{He}^{3}$. The specific heats are determined by applying a measured amount of current to a constantan heater on the sample for an accurately measured length of time. With additional information determined before the experiment for the resistance of the heater, the heat capacity of the empty calorimeter, and the number of moles (or grams) of sample, the specific heat can be determined when the temperature increase due to the heat input is known.

The temperature is determined by measuring the resistance of a carbon thermometer arranged in a four-lead potentiometer circuit. One pair of leads is used to measure the voltage across the thermometer and the other pair carries the thermometer current; this current also flows through a standard resistor, and the voltage developed is measured to determine this current.

Figure 1 shows how this temperature increase is actually determined. Because of unavoidable heat leaks, the temperature of the sample does not remain constant between heating periods, but drifts at a slow rate (assumed to be linear). For this reason, the drifts before and after the heating period are measured as shown in Figure 1. Point $C$ represents the point where heat is turned on, and $D$ represents the point where it is turned off.

*Lounasmaa, O. V., and Guenther, R. A., Phys. Rev. 126, May 15, 1962. 


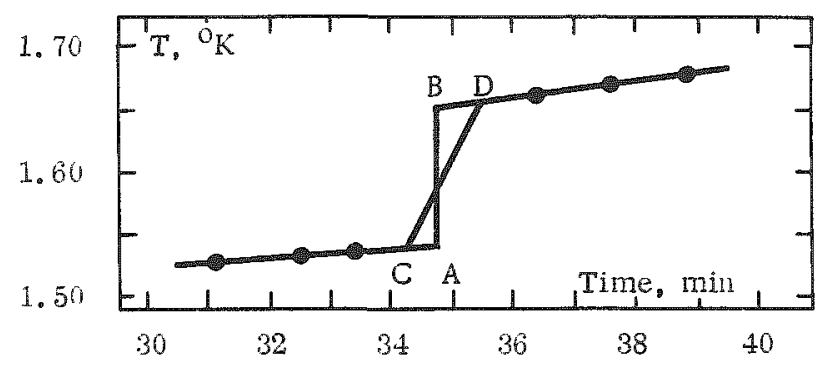

Figure 1

Fore- and after-drifts of a typical heat capacity point

The true temperature increase due to the electrical heating is then found by extrapolating the fore- and after-drifts to the middle of the heating interval, giving points $A$ and $B$, respectively. The difference in the temperatures of points $A$ and $B$ gives the increase due to the heating, and the mean of these temperatures gives the temperature to which the specific heat is referred.

The carbon thermometer is calibrated against the vapor pressures of $\mathrm{He}^{3}$ and $\mathrm{He}^{4}$ by direct vapor pressure measurements where possible and by means of a magnetic thermometer for lower temperatures. Measurements of vapor pressures are done with oil manometers (containing di-n-butyl phthalate) for low pressures and mercury manometers for higher pressures. These readings are then corrected by the program for the relative expansion effects of room temperature on the glass, mercury, and oil, and for the zero corrections of the mercury manometers (see PROGRAM DETAILS). Also included is a correction to standard gravity of $980.665 \mathrm{~cm} / \mathrm{sec}^{2}$, assuming a local value of $980.278 \mathrm{~cm} / \mathrm{sec}^{2}$, and a correction for impurities in the $\mathrm{He}^{3}$. The latter correction is applicable for small $\mathrm{He}^{4}$ impurities in the $\mathrm{He}^{3}$; the correction factor would be $\mathrm{l}-\mathrm{x}$ if $\mathrm{x}$ were the percent of $\mathrm{He}^{4}$ in the $\mathrm{He}^{3}$. The pressures obtained are then referred to $\mathrm{He}^{3 *}$ or $\mathrm{He}^{4 * *}$ vapor pressure tables to obtain values of absolute temperature.

For temperatures too low to yield vapor pressure readings, a magnetic thermometer calibrated at higher temperatures is used. From measurements of the mutual inductance of the magnetic thermometer along with values of temperature determined from vapor pressure readings, a formula is determined for the points of the form

* Sydoriak, S. G., and Roberts, T.R., Phys. Rev. 106, 175 (1957)

(temperatures converted from $T_{55}$ to $T_{58}$ ).

**Van Dijk, H., Durieux, M., Clement, J.R., and Logan, J. K., J. Res. Nat. Bur. Stand. 64A, No. 1, (1960). 


$$
\kappa=A+\frac{B}{T+(\alpha / T)+\beta},
$$

where $K$ is the mutual inductance of the magnetic thermometer, $T$ is the absolute temperature, $A$ and $B$ are the parameters to be determined (by the method of least squares), $\alpha$ is an input constant, and $\beta$ is a constant chosen by the program to give the best fit to the experimental points.

When the constants $A$ and $B$ have been determined, the above formula is inverted and then extrapolated to determine values of temperature corresponding to values of $k$ in the region too low for helium vapor pressure readings.

The result of the previous calculations is to provide a value of absolute tempexature for each value of resistance of the carbon thermometer. The next step is to fit a formula to these data by the method of least squares. For this purpose there are available in the program 33 functions of $\mathrm{R}$, any combination of which can be used to comprise the calibration formula. The final result of this analysis is then a formula

$$
\frac{1}{\mathrm{~T}}=A f_{1}(\mathrm{R})+\mathrm{Bf}_{2}(\mathrm{R})+\cdots+\mathrm{Nf}_{\mathrm{n}}(\mathrm{R})
$$

where $A, B, \cdots, N$ have been determined from the calibration points $R_{\mathbb{1}}$ $T_{1}, \cdots, R_{m}, T_{m}$ by the method of least squares.

As the final step in the analysis, a formula whose form can be any polynomial in powers of $T$ is fitted to the specific heat data by the method of least squares. At the same time, the data are corrected for the effect of curvature of the specific heat function. This is necessary because of the finite intervals of temperature used in the measurements and the fact that over such an interval the specific heat function is perhaps not sufficiently linear to yield a completely accurate answer without correction. The leastsquares analysis includes the provision for fitting the specific heat data with any combination of terms whose coefficients are floating and free to be determined by the method of least squares, and terms whose coefficients are fixed and entered as input to the program.

\section{OPERATION}

\section{A. Specific Heat Calculation Program}

\section{Input}

a. Calibration Data. Title Card. The first card to be read by the machine is a title card. The information on this card will be duplicated 
in all the data output of the same experiment. The first 72 spaces of the card are available for information.

Constants Card. The second card read in by the machine is a constants card containing information necessary for the calibration calculations. It contains the following data:

Word 1: Number of calibration points.

(col, 8-9)

Word 2: Constant $\alpha$ for the magnetic thermometer formula (col. 10-20) [formula (1)].

Word 3: Zero correction for $\mathrm{He}^{3}$ mercury manometer in $\mathrm{mm}$ (col. 21-31) of mercury.

Word 4: Zero correction for $\mathrm{He}^{4}$ mercury manometer in $\mathrm{mm}$ (col. 32-42) of mercury.

Word 5: Purity correction for $\mathrm{He}^{3}$ manometer readings (col. 43-52) (e.g., 0.994 if there were $0.6 \% \mathrm{He}^{4}$ in the $\mathrm{He}^{3}$ ).

Word 6: Value of standard resistor used to measure carbon (col.53-62) thermometer current, in ohms.

Calibration Data Cards. The next cards read in by the machine are the calibration data cards; these contain data as follows:

Word 1: $\quad$ Lower helium vapor pressure manometer reading in (col.1-9) $\mathrm{mm}$ of oil or mercury.

Word 2: Higher helium vapor pressure manometer reading in (col.10-20) $\mathrm{mm}$ of oil or mercury.

Word 3: Mutual inductance bridge reading (if any) for magnetic (col.21-31) thermometer.

Word 4: Voltage reading of current in carbon thermometer. $(\operatorname{col} .32-42)$

Word 5: Voltage reading of carbon thermometer.

(col. 43-52)

Word 6: Reading of room temperature in ${ }^{\circ} \mathrm{C}$. (col. 53-62)

Word 7: Code number from 1 to 5 identifying nature of (col.65) calibration data. $1=\mathrm{He}^{3}$ oil; $2=\mathrm{He}^{3}$ mercury: $3=\mathrm{He}^{4}$ oil $; 4=\mathrm{He}^{4}$ mercury: $5=$ no manometer reading. 
Word 8: Code word as follows:

(col.68-72) Col. 68: Experiment number.

Co1. 69: Run number (zero if calibration data).

Col. 70-72: Calibration point number.

Calibration Formula Card. The last card comprising the calibration input contains the data for the calibration formula [formula (2)] as follows:

Word 1: Number $\mathrm{n}$ of functions to be used for calibration (col.9) formula.

Words $2,3,4,5,6,7,8$, and 9 are in columns $15-16,19-20,26-27$, $30-31,36-37,41-42,46-47$, and 51-52, respectively, and contain the code numbers of the functions to be used for the calibration curve as follows (as many words as necessary, up to 8):

$\begin{array}{lll}1: 1 / R^{5} & 2: 1 / R^{4} & 3: 1 / R^{3} \\ \text { 4: } 1 / R^{5 / 2} & 5: 1 / R^{2} & 6: 1 / R^{3 / 2} \\ \text { 7: } 1 / R & 8: 1 / R^{1 / 2} & 9: 1 \\ \text { 10: } R^{1 / 2} & 11: R & 12: R^{3 / 2} \\ \text { 13: } R^{2} & 14: R^{5 / 2} & 15: \mathrm{R}^{3} \\ \text { 16: } \mathrm{R}^{4} & 17: \mathrm{R}^{5} & 18: \mathrm{e}^{-\mathrm{R} / 2} \\ \text { 19: } \mathrm{e}^{-\mathrm{R}} & 20: \mathrm{e}^{-2 R} & 21: \mathrm{e}^{-3 R} \\ \text { 22: } \mathrm{e}^{\mathrm{R} / 2} & 23: \mathrm{e}^{\mathrm{R}} & 24: \mathrm{e}^{2 \mathrm{R}} \\ \text { 25: } \mathrm{e}^{3 R} & 26:(\ln R)^{-1 / 2} & 27:(\ln R)^{-1} \\ \text { 28: }(\ln R)^{-2} & 29:(\ln R)^{-3} & 30:(\ln R)^{1 / 2} \\ \text { 31: } \ln R & 32:(\ln R)^{2} & 33:(\ln R)^{3}\end{array}$

b. Specific Heat Data. Number of Runs Card. The first card read in gives the number of runs in the experiment. This is in column 9.

This is followed by the data for each run, one after another, each run containing the following data:

Number of Points Card. The first card of each run gires the number of specific heat points for that run in columns $8-9$.

Constants Card. The second card gives the constants used in calculating the specific heats as follows: 
Word 1: Constant $x$ of the formula for the heater resistance

(col. 1-9) $\mathrm{R}=\mathrm{r}+\mathrm{sT}$, in ohms.

Word 2: Constant $s$ of the formula for the heater resistance

(col. 10-20) $\mathrm{R}=\mathrm{r}+\mathrm{sT}$, in ohms $/{ }^{\circ} \mathrm{K}$.

Word 3: Value of standard resistor used to measure heating

(col. 21-31) current in ohms.

Word 4: Value of standard resistor used to measure thermom-

(col. 32-42) eter current, in ohms.

Word 5: Constant A of the formula for the heat capacity of the

(col. 43-52) empty calorimeter $\mathrm{C}=\mathrm{AT}^{3}+\mathrm{BT}$, in millijoules $/\left({ }^{\circ} \mathrm{K}\right)^{4}$.

Word 6: Constant $B$ of the formula for the heat capacity of the

(col. 53-62) empty calorimeter $\mathrm{C}=\mathrm{AT}^{3}+\mathrm{BT}$, in millijoules $/\left({ }^{\circ} \mathrm{K}\right)^{2}$.

Word 7: Number of moles of sample.

(col. 63-72)

The next cards of the run are the actual specific heat input consisting of drift data and heating period data alternately.

Drift Data Card(s). The drift data is made up on as many cards as necessary (up to 4) as follows:

Word 1: Number of drift points (if more than one card for drift, (col. 8-9) this number will appear on first card only).

Word 2: Voltage of carbon thermometer.

(col. 10-20)

Word 3: Time reading for previous voltage measurement.

(col. 25-31) Col. 25: hours; col. 26-28: minutes; col. 29-31:

seconds.

Word 4: Voltage of carbon thermometer.

(col. $32-42)$

Word 5: Time reading for previous voltage measurement.

(col. 46-52) Col.46: hours; col.47-49: minutes; col. 50-52: seconds.

Word 6: Voltage of carbon thermometer.

(col. 53-62)

Word 7: Time reading for previous voltage measurement.

(col. 66-72) Col.66: hours; col.67-69: minutes; col. 70-72:

seconds. 
Heating Period Card. The heating period data is made

up as follows:

Word 1: Voltage reading of current in carbon thermometer

(col. 1-9) at some time during previous drift period.

Word 2: Time reading for previous current measurement.

(col. 14-21) Col. 14: hours; col. 15-17: minutes; col. 18-20: seconds.

Word 3: Time reading at beginning of heating period. Col. 25:

(col.25-31) hours; col.26-28: minutes; col. 29-31: seconds.

Word 4: Voltage reading of heating current, in volts.

(col. $32-42$ )

Word 5: Length of heating period. Col. 46-49: seconds;

(col. 46-52) col.50-52: sixtieths of a second.

Word 6: Code word as follows:

(col.58-62) Col. 58: Experiment number.

Col. 59: Run number.

Col. 60-62: Specific heat point number.

The last card of a run is a heating period card containing only the information of the first two words.

2. Machine Operation.

Reader: Standard 72-column.

Punch: Standard 72-column; used only when switch 6 is UP.

Printer: Standard SHARE 2 board; used only when switch 6 is UP.

Sense Switch Settings:

1: UP unless it is desired to stop after completion of calibration curve calculations.

2: UP unless it is desired to read input data (including $\mathrm{He}^{3}$ and $\mathrm{He}^{4}$ tables) from tape 2.

6: UP unless it is desired to put output on tape 6. The sense switch settings are interrogated repeatedly during input and output, and a change in their settings is usually immediately effective.

Tapes: Tape 2 contains input (including $\mathrm{He}^{3}$ and $\mathrm{He}^{4}$ tables) with switch 2 DOWN.

Tape 6 receives output with switch 6 DOWN. 
Off-line Processing: Print and punch from tape 6 under program control.

Running Procedure: "Ready" code deck followed by $\mathrm{He}^{3}$ and $\mathrm{He}^{4}$ tables and data deck in card reader if switch 2 is UP.

If switch 2 is DOWN: "Ready" code deck in card reader and "Ready" data tape 2 .

"Clear"

"Load Cards"

Problem is completed when all data are entered and HPR 77777 appears in storage lights.

To run data from another experiment without loading in code deck and $\mathrm{He}^{3}$ and $\mathrm{He}^{4}$ tables again:

If switch 2 is UP: "Ready" data deck in card reader.

Console switches: 000000000115

If switch 2 is DOWN: "Ready" data tape 2.

Console switches: 000000000225

Automatic-Manual Switch: Manual

"Enter Instruction"

Automatic-Manual Switch: Automatic

"Start"

Problem is completed as above.

3. Output

a. Magnetic Thermometer. This output gives first the values of the constants $\mathrm{A}$ and $\mathrm{B}$ determined by the least-squares analysis for the magnetic thermometer calibration curve, then the value of $\beta$ which it was determined gave the best fit to the calibration formula [formula (1)].

After this, the values of $T, R$, and $\kappa$ for the calibration points used in the least-squares analysis above are given along with the deviations of the experimental values of $k$ from the smooth curve. This deviation is of the form $\kappa$ (formula evaluated at experimental temperature) $\kappa$ (experimental). Also given for each point is the code word for that point as described under input.

b. Calibration. For the main calibration curve the output consists of the coefficients as determined by the least-squares analysis, each coefficient followed by the code number for the function of $R$ to which 
it applies. Then data for the actual calibration points are listed; the value of temperature, resistance, and two forms of the deviation of the experimental points from the formula determined are put out for each calibration point.

c. Specific Heat Analysis. For each experimental heating period, a specific heat point is calculated; the output of this calculation consists of the specific heat (not curvature corrected), the mean temperature, and the temperature increase $\Delta T$ for the heating period. Also included is a number indicating how well the temperature drift following the heating period is fitted by the straight line put through the drift points. This number is the mean of the square of the deviations of the experimental points from the straight line.

\section{B. Curvature Correction Program}

\section{Input}

The input to the curvature correction program consists primarily of the output of the specific heat calculation program. For each run of the previous specific heat calculations, the punched card output for that run contains the data, not only for the point plotter, but also for the input to the curvature correction program. The code word on these cards, in col. 51-60, serves to identify the data on the cards for the purpose of eliminating any points before proceeding with the least-squares fit of the data in the present program.

Title Card. The first card read in by the curvature correction program is a title card for the data. For this purpose. a title card is punched out for each run by the previous program. Care must be taken, therefore, to remove any extra title cards from the input data to the curvature correction program in the case that more than one run is being combined as input.

contains the following: The second card read in by the program

Word 1: The total number of specific heat points (up to 200) (col. 7-9) being put in as input.

Word 2: The number of terms (up to 7) with floating coefficients (col.20) desired to be used in the least-squares analysis.

Word 3: The number of terms (up to 7) with constant coefficients (col. 31) desired to be used in the least-squares analysis.

Specific Heat Cards. The next cards read in are the desired number of specific heat cards as calculated and punched out from the previous program. 
After the specific heat cards are the three cards specifying the actual formula to be used in fitting the specific heat points. All three cards are arranged in the same manner: words 1, 2, 3, 4, 5, 6, and 7 are in columns $1-9,10-20,21-31,32-42,43-52,53-62$, and 63-72, respectively.

Powers of $T$, Variable Coefficients. The first of these cards gives the powers of $T$ for the terms of the formula whose coefficients are floating. This will require as many words on the card (up to 7) as are indicated in word 2 of the specifications card.

Powers of $T$, Constant Coefficients. The second card gives the powers of $T$ for the terms of the formula whose coefficients are fixed. This will require as many words on the card (up to 7) as are indicated by word 3 of the specifications card.

Constant Coefficients Card. The last card of the curvature correction input gives the fixed coefficients of the terms of the formula whose powers of $\mathrm{T}$ are given in the corresponding word of the previous card.

2. Machine Operation

Reader: Standard 72-column.

Punch: Standard 72-column; used only when switch 6 is UP.

Printer: Standard SHARE 2 board; used only when switch 6 is UP.

Sense Switch Settings:

2: UP unless it is desired to read input from tape 2.

6: UP unless it is desired to put output on tape 6.

Tapes: Tape 2 contains input for use with switch 2 DOWN.

Tape 6 receives output with switch 6 DOWN.

Off-line Processing: Print and punch from tape 6 under program control.

Running Procedure: "Ready" code deck followed by data deck in card reader if switch 2 is UP.

If switch 2 is DOWN: "Ready" code deck in card reader and "Ready" data tape 2.

"Clear"

"Load Cards" 
Problem is completed when HPR 77777 appears in storage lights.

To run program again with different data without loading in code deck again:

"Ready" data deck in card reader if switch 2 is UP.

If switch 2 is DOWN: "Ready" data tape 2.

Console switches: 000000000027

Automatic-Manual Switch: Manual

"Enter Instruction"

Automatic-Manual Switch: Automatic

"Start"

Problem is completed as above.

\section{Output}

The output of the curvature correction program gives the powers of $T$ for which coefficients were determined by the least-squares analysis, the coefficients themselves, and the standard deviations of the coefficients. Also printed out for reference are the powers of $T$ which had fixed coefficients along with those coefficients. Then is printed out the final values of specific heat which have now been curvature corrected, the mean temperatures for these specific heats, the temperature intervals of the heating period, and the deviations of the corrected specific heats from the smooth function determined by the least-squares analysis.

\section{Point Plotter}

For speed and accuracy in plotting the intermediate and final results of the various calculations performed by the program, the outputs of the several parts of the program have been made to include cards which can be fed into the Electronic Associates, Inc. DATAPLOTTER for automatic plotting of the points. In all cases, the data for the point plotter have been normalized in such a fashion that the largest number of any group or run is scaled until it is between 1.0 and 0.1 and the rest of the numbers of the group are scaled by the same factor. In this way, all input to the point plotter is in the for $\pm 0 . X X X X X X X X$ of which only the first four significant digits are used by the point plotter. This arrangement is necessary in order that the sign of the number is always in the same column of the card. However, it means that, when plotting data from several runs, different runs may be scaled differently and, therefore, the scale factor of the point plotter must be changed accordingly. 
The contents of the output cards from the various parts of the program are as follows:

\begin{tabular}{|c|c|c|c|c|c|c|}
\hline M.T. & $T$ & $K(F)-K(E)$ & $\mathrm{R}$ & KAPPA & OMIT & CODE \\
\hline C. & $T$ & $T(E)-T(E)$ & R & $\frac{1}{T(F)}-\frac{1}{T(E)}$ & OMIT & CODE \\
\hline S.H. & $\mathrm{T}$ & $\mathrm{C}$ & (c) & (T) & (DELTA T) & CODE \\
\hline C.C. & $T$ & C & $C(F)-C(E)$ & & OMTT & CODE \\
\hline DATA & $\pm 0 . \times \times \times \times \times x$ & $\pm 0 . X \times X X \times X$ & $\pm 0 . \times \times \times \times \times \times$ & $10 . \times \times \times X \times x \times$ & 1.0 & ERnnn \\
\hline CARD & 12345678 & 0123456789 & 123456789 & 01234567890 & 7890 & +567890 \\
\hline COL. & & 1 & & 14 & 5 & 6 \\
\hline
\end{tabular}

M. T. = Magnetic Thermometer Data

C. = Calibration Data

S.H. = Specific Heat Data

C.C. = Curvature Correction Data

The quantities in parentheses are those for the input to the curvature correction program and are not adapted for use on the point plotter.

The quantity marked OMIT consists of either a one or a zero, depending on whether the point in question has been used in the calculations or has been omitted, respectively. It is intended to be used for controlling the point symbol by which means omitted points would be indicated by a different symbol from the rest.

\section{Operating Instructions}

a. Place suitable graph paper on table of plotter. By hand, move arm up and down over paper until paper is lined up properly (path of cursor should be parallel to a vertical line). Turn VACUUM switch ON. Smooth out paper.

positions:

b. The following switches should be placed in the indicated

Switch

Position

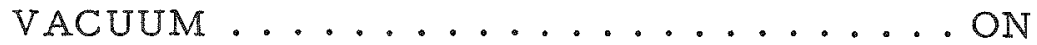

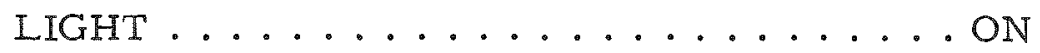

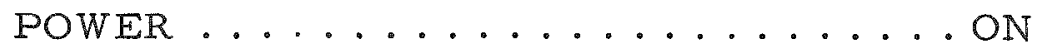

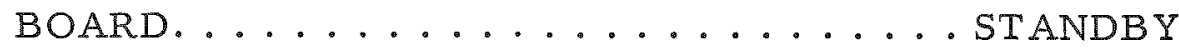

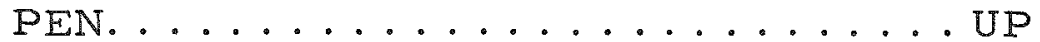

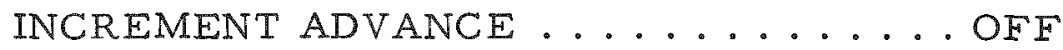

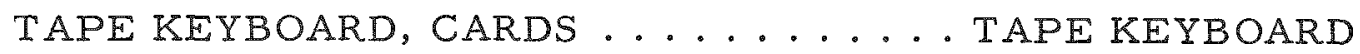

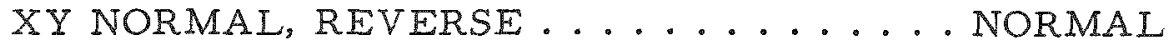

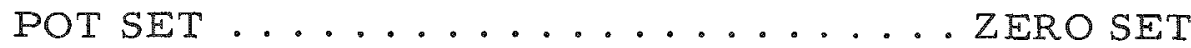

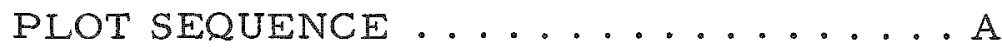




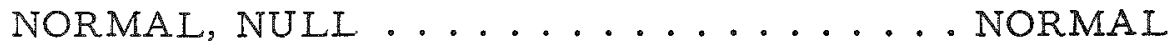

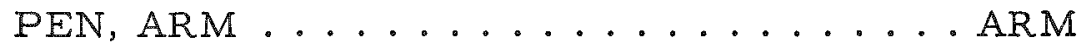

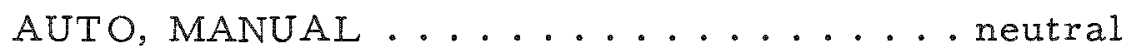

c. Then, as follows:

BOARD.................. OPERATE

INCREMENT ADVANCE ........... RESET

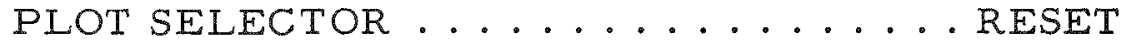

Rotate NULI SENSITIVITY . . . . . . . . completely clockwise

Depress STORAGE CLEAR

Depress STOP

d. Free locks on pen and arm helipots. By turning helipot knobs, set head above point of desired origin. Call this point $\left(x_{0}, y_{0}\right)$. Lock helipots. Depress RESET switch. Point $\left(x_{0}, y_{0}\right)$ has just been plotted.

e. Of the points to be plotted, select one nearest limit of machine. Call this point $(\mathrm{xm}, \mathrm{ym})$. Manually position head over location of this point.

Note: $\mathrm{x}_{\mathrm{m}}, \mathrm{ym}_{\mathrm{m}}$ must be greater than zero.

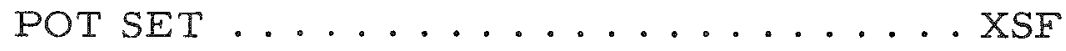

Depress STORAGE CIEAR

Type into keyboard: $\mathrm{X}$, sign, $\left|\mathrm{x}_{\mathrm{m}}-\mathrm{x}_{0}\right|$, PLOT

Note: on keyboard, $t=0$

$$
-=1
$$

Wait until null indicator light goes out.

POT SET . . . . . . . . . . . . YSF

Type into keyboard: $Y$, sign, $\left|y_{m}-y_{0}\right|$, PLOT

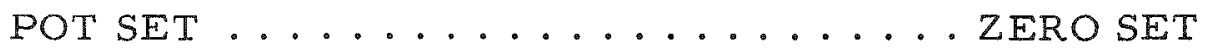

Depress STOP

Depress RESET

Point $\left(\mathrm{x}_{\mathrm{m}}, \mathrm{y}_{\mathrm{m}}\right)$ has just been plotted.

Depress STORAGE CLEAR

Depress STOP

Depress RESET

Point $\left(\mathrm{x}_{0}, \mathrm{y}_{0}\right)$ has again been plotted. 
f. With head at position $\left(\mathrm{x}_{0}, \mathrm{y}_{0}\right)$,

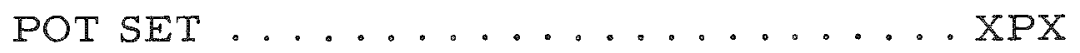

Type into keyboard $X$-Parallax: $X$, sign, $\left|x_{0}\right|$, PLOT

Wait until null indicator light goes out.

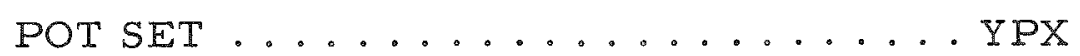

Type into keyboard Y-Paxallax: Y, sign, $\left|y_{0}\right|, P L O T$

When light goes out,

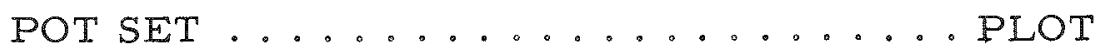

The machine is now ready to accept points to plot.

Note: If the null indicator light fails to go out, set the BOARD switch to STANDBY, depress the STOP and RESET buttons, and return BOARD to OPERATE。

The available point symbols are the following:

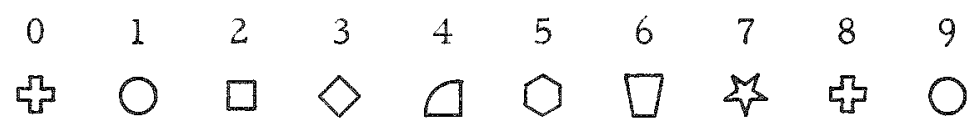

To change point symbol, depress and keep down SYMBOL ADVANCE button, type into keyboard the appropriate number, release button.

\section{Data Input (IBM Cards)}

Card format is controlled by the board-wiring in the IBM-523 Summary Card Punch (card reader) as follows: number the first twelve horizontal entry points under COMP MAG OR CTR. TOT. EXIT OR M.S. IN as $1,2, \cdots, 12$. Then pulses to points $1-4$ are interpreted as $X$-digits, $5-8$ as $Y$-digits, 9 as the sign of X, 10 as the sign of $Y, 11$ as the symbol advance, and 12 as a control code (not used). Wire these holes from the desixed card columns under PUNCH BRUSHES.

\section{PROGRAM DETAILS}

\section{A. Magnetic Thermometer Calculation}

It is in this paxt of the program that the manometer pressure readings are converted to values of absolute temperatures. The formulas for converting the manometer readings to readings of absolute pressure in $\mathrm{mm}$ of mercury are: 
For $\mathrm{He}^{3}$ oil readings: $\quad P=\left(P_{2}-P_{1}\right)(0.078062-0.000058 t) / C$

For $\mathrm{He}^{3} \mathrm{Hg}$ readings. $\quad P=\left(P_{2}-P_{2}-Z\right)(0.999428-0.000172 t) / C$

For $\mathrm{He}^{4}$ oil readings: $\quad P=\left(P_{2}-P_{1}\right)(0.078062-0.000058 t)$

For $\mathrm{He}^{4}$ Hg readings: $\quad P=\left(P_{2}-P_{1}-Z^{\prime}\right)(0.999428-0.000172 t)$,

where $P_{2}$ and $P_{1}$ are the manometer readings, $t$ is the room temperature in ${ }^{\circ} \mathrm{C}, \mathrm{C}$ is the correction factor for $\mathrm{He}^{3}$ purity, $\mathrm{Z}$ is the $\mathrm{He}^{3}$ mercury manometer zero correction, and $\mathrm{Z}^{\prime}$ is the $\mathrm{He}^{4}$ mercury manometer zero correction.

From the values of pressure thus determined, a table look-up is performed and a parabolic interpolation is made, using three adjacent points of the table. The $\mathrm{He}^{3}$ table consists of values of absolute temperature and pressure in $\mathrm{mm}$ of $\mathrm{Hg}$ at intervals of 1 millidegree from 0.7 to $0.9^{\circ} \mathrm{K}, 5$ millidegrees from 0.9 to $1.4^{\circ} \mathrm{K}$, and 10 millidegrees from 1.4 to $2.19^{\circ} \mathrm{K}$; the $\mathrm{He}^{4}$ table has values at intervals of 10 millidegrees from 1.4 to $4.39^{\circ} \mathrm{K}$. The points from the table used for the interpolation consist of two points above and one point below the unknown point. This means that $\mathrm{He}^{3}$ points above $2.1792^{\circ} \mathrm{K}$ and $\mathrm{He}^{4}$ points above $4.38^{\circ} \mathrm{K}$ exceed the effective limits of the tables.

In the least-squares analysis for the magnetic thermometer, the constant $\beta$ of formula ( 1 ) is varied by units of 0001 from -0.010 to +0.021 ; the value of $\beta$ is picked which results in values of $A$ and $B$ from the leastsquares analysis giving the best fit to the experimental points.

The least-squares analysis for the magnetic thermometer also has the provision for eliminating from the analysis those points whose deviations are abnormally large and which are therefore likely to be in error. This is done by performing the least-squares analysis once and then comparing the deviation of each point from the smooth curve thus determined with the deviations of the points imme liately adjacent to the point. If the square of the deviation of the point in question is more than nine times the mean of the squares of the deviations of the two preceding and the two following points, then the point is thrown out and the analysis is repeated without it. Because of the nature of this elimination procedure, the two points at the beginning and the two at the end of a set of points are not considered for elimination.

\section{B Calibration}

The calibration calculations are done in double precision to as sure greater accuracy; the routine used is the General Electric Fortran II Double-Precision Floating Point Package GD-A-01-1. The least-squares analysis performed for the calibration curve has the same provision as described above for throwing out points whose deviations are too large. 
In the least-squares analysis, the points used are weighted, the weight of each point being proportional to $T$ so that, other things being equal, the deviations in $\mathrm{T}$ will tend to be proportional to $\mathrm{T}$ [the analysis is performed with a formula of the form $1 / T=f(R)$ ].

\section{Specific Heat Analysis}

In the calculations of the specific heats, the program first calculates the constants for the straight lines of the fore-and after-drifts. From the equations for the drifts can be found the resistance of the carbon thermometer before and after the heat input extrapolated to the middle of the heating time. The method for this can be seen from the following analysis:

If the carbon thermometer circuit is considered as an impressed voltage $E_{b}$ across a combination of the thermometer resistance $R_{T}$ in series with another resistance $R_{S}$, then the current $I$ flowing in the circuit can be expressed as

$$
I=\left(E_{\mathrm{b}}-E_{T}\right) / R_{\mathrm{s}} \quad,
$$

where $E_{T}$ is the voltage appearing across the carbon thermometer. If the voltage across the thermometer at some time is found to be $E_{T_{1}}$, and the current flowing through it at the same time is $I_{1}$, and if $E_{T_{2}}$ and $I_{2}$ are the voltage and current at some later time, then by a series of substitutions in equation (7), the following equation can be derived:

$$
R_{T}=\frac{E_{T}\left(E_{T_{1}}-E_{T_{2}}\right)}{\left(I_{1}\left(E_{T}-E_{T_{2}}\right)-I_{2}\left(E_{T}-E_{T_{1}}\right)\right.} .
$$

If, therefore, current readings $I_{1}$ and $I_{2}$ are taken at times $t_{1}$ and $t_{2}$ (one during each drift period), respectively, then the values of $E_{T_{1}}$ and $E_{T_{2}}$ can be determined by evaluating the fore-drift equation at $t=t_{I_{1}}$ and the afterdrift equation at $t=t_{I}$, respectively. With these values, equation (8) can be used to find the resistance of the carbon thermometer for any values of $E_{T}$, in particular those values obtained by extrapolating the temperature drifts to the middle of the heating period. The calibration formula is then used to find the temperatures of these two points. This immediately yields the mean temperature and the temperature increase $\Delta T$. It is a simple matter then to use this to calculate the specific heat according to the formula

$$
C=\frac{\frac{I^{2}(r+s T) t}{\Delta T}-\left(A T^{3}+B T\right)}{M}
$$

where $I$ is the heating current, $r$ and $s$ are the constants for the heater resistance, $T$ is the mean temperature, $t$ is the length of the heating period, $A$ and $B$ are the constants for the heat capacity of the empty calorimeter. and $M$ is the number of moles of sample. 
D. Curvature Correction

If the true specific heat of a substance follows the formula

$$
\mathrm{C}=\mathrm{AT} \mathrm{T}^{\mathrm{a}}+\mathrm{B} \mathrm{T}^{\mathrm{b}}+\cdots+\mathrm{NT^{ \textrm {n } }}
$$

then the amount of heat put into the substance to cause a temperature rise from $T_{1}$ to $T_{2}$ would be

$$
\begin{aligned}
q= & \int_{T_{1}}^{T_{2}}\left(A T^{a}+B T^{b}+\cdots+N T^{n}\right) d T \\
= & \frac{A}{a+1}\left(T_{2}^{a+1}-T_{1}^{a+1}\right)+\frac{B}{b+1}\left(T_{2}^{b+1}-T_{1}^{b+1}\right)+\cdots \\
& +\frac{N}{n+1}\left(T_{2}^{n+1}-T_{1}^{n+1}\right) \quad(\text { providing } a, b, \cdots, n \neq-1) .
\end{aligned}
$$

The specific heat as calculated by the previous program would then be

$$
\begin{aligned}
C^{*}= & \frac{q}{T_{2}-T_{1}}=\frac{A\left(T_{2}^{a+1}-T_{1}^{a+1}\right)}{(a+1)\left(T_{2}-T_{1}\right)}+\frac{B\left(T_{2}^{b+1}-T_{1}^{b+1}\right)}{(b+1)\left(T_{2}-T_{1}\right)}+\cdots \\
& +\frac{N\left(T_{2}^{n+1}-T_{1}^{n+1}\right)}{(n+1)\left(T_{2}-T_{1}\right)} .
\end{aligned}
$$

Therefore, if the values of $C^{*}, T, T_{2}-T_{1}$, and $a, \cdots, n$ are known (these will be recognized as the input to the curvatuxe correction program), then a least-squares analysis can be performed on the basis of this equation to determine directly the coefficients $A, B, \cdots, N$. When the coefficients $A$, $B, \cdots, N$ have been determined, then for any experimental value of $C^{*}, T$, and $T_{2}-T_{1}$, the true, corrected experimental specific heat is

$$
\begin{aligned}
C= & C^{*}+A T^{a}+B T^{b}+\cdots+N T^{n}-\frac{A\left(T_{2}^{a+1}-T_{1}^{a+1}\right)}{(a+1)\left(T_{2}-T_{1}\right)} \\
& -\frac{B\left(T_{2}^{b+1}-T_{1}^{b+1}\right)}{(b+1)\left(T_{2}-T_{1}\right)}-\cdots-\frac{N\left(T_{2}^{n+1}-T_{1}^{n+1}\right)}{(n+1)\left(T_{2}-T_{1}\right)} .
\end{aligned}
$$

In performing the least-squares analysis for this part of the program, points with too large a deviation from the smooth curve are thrown out in the same manner as has been described for the previous least-squares calculations.

To prevent loss of accuracy occurring in the solution of the normal equations, double precision is also used in the calculations for this part of the program. 


\section{PROGRAM STOPS}

The following list gives the SAP code for each program stop, along with the Fortran statement number of the stop instruction and the Fortran statement number of the instruction causing the transfer to the stop command.

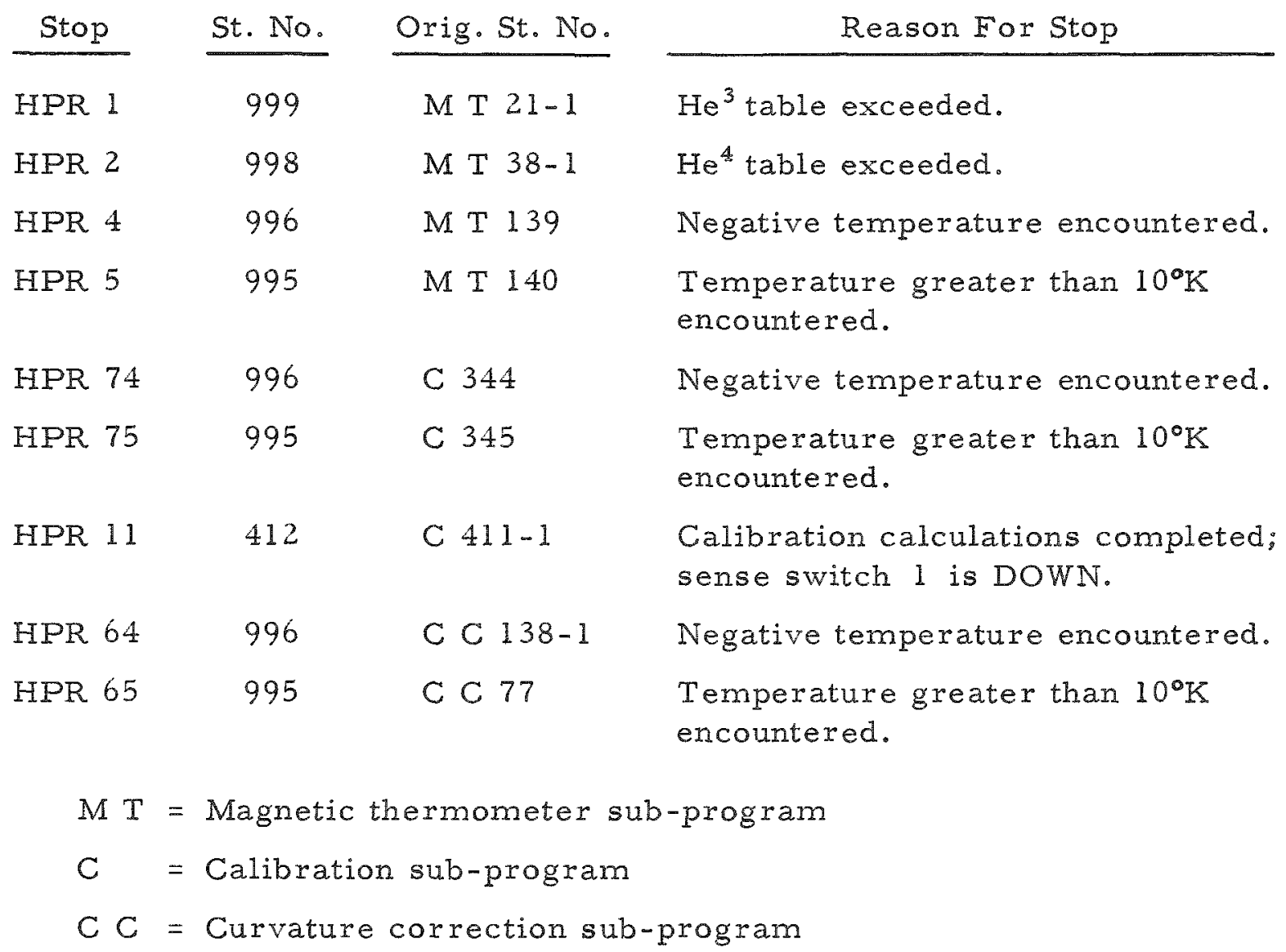




\section{PROGRAM LISTING}

MAGNETIC THERMOMETER SUBPROGRAM

DIMENSION TABLES $(2,380)$, TABLE $4(2,300), B(8,9), A(8,9), C O E F C(8)$. IR(100), T(100),OMIT(100), THERM(100),KIND $(100), N C O D E(100), D E V(100)$. 2TDEV (100), LSFN $(8), F(8), A R G(4), S C A L E(4), N A M E(12)$

COMMON R, T, NAME, NCODE, LSFN,F, COEFC

IF ISENSE SWITCH 2$) 2,4$

4 READ $1,(1$ TAPLES(I, J), I= 1,2$), J=1,380),(1$ TABLE4 $(I, J), I=1,2), J=1,300)$

READ 3, (NAME $11,1=1,12)$

READ 5, NUMBER, ALPHA, HSHGZC,H4HGZC,H3PURC, RSTANR GO TO 9

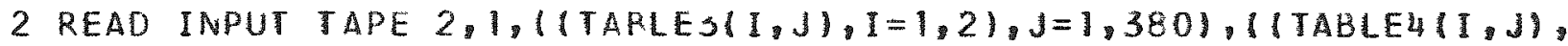
$I I=1,2), J=1,3001$

1 FORMAT (5IFT.4,FT.3))

READ INPUT TAPE $2,3,(N A N E(1) 1=1,12)$

3 FORMAT (12A6)

READ INPUT TAPE 2,5, NUMBER, ALPHA, HSHGZC,H4HGZC,H3PURC, RSTANR

5 FORMAT $(I 9, F\|1,6, F|1.2, F \|, 2, F| 0.6, F 10.2)$

9 DO $52 \quad I=1$, NUNBER

IF (SENSE SWITCH 2) 6,7

7 READ 8,PRESS 1, PRESS2, THERMII),CURR, VOLT, RTEMP, KINDIII, NCODE (I) GO TO 10

6 READ INPUT TAPE 2,8, PKESS 1, PRESS2, THERM(I),CURR, VOLI, RTEMP,

IKIND(I), NCODE(I)

8 FORMAT $(F 9.2, F 11,2, F 11,2, F \mid 1,2, F 10.2, F 10.1,13,17)$

10 KINDI $=$ KIND(I)

$6010(11,13,15,17,52), K I N D I$

$11 \mathrm{HSPRES}=($ PRESS2-PRFSS1)*10.018062-0.000058*RTEMP //H3PURC

GO TO 19

13 H3PRES = (PRES S2-PRESS 1-H3HG7C):10.999428-0.000172 2 RTEMP I/H3PURC

$G O$ TO $1 Y$

15 H4PRES $=($ PRESS2-PRESS1)*(0.078062-0.000058*R TEMP $)$

GO TO 36

17 H4PRES = (PRESS2-PKESS 1-H4HCZC) $10.999428-0.000172 *$ TEMP)

$G 0$ TO 36

19 DO $21 \mathrm{~J}=2.379$

IF (TABLE3!1,J)-H3PRES) $21,23,25$

21 CONTINUE

6010999

$23 T(I)=T A B L E 3(2, J)$

60 TO 52

$25 B(1,1)=$ TABLF $3(1, J)-T A B L E 3(1, j-1)$

$B(1,2)=B(1,1) * B(1,1)$

$B(1,3)=\operatorname{TABLE} 3(2, j)-T A B L F 3(2, j-1)$

$B(2,1)=$ TABLE $3(1, j+1)-\mathbb{A} A B L E 3(1, j-1)$

$B(2,2)=B(2,1) \div B(2,1)$

$B(2,3)=\operatorname{TABLE} 3(2, \mathrm{j}+1)-1 A B L E 3(2, \mathrm{~J}-1)$

DENOM $=6(1,1) *(2,2)-B(2,1) * B(1,2)$

BINT $=(B(1,3) \div B(2,2)-B(2,3) * B(1,2) / / D E N O M$

CINT $=(B(1,1) \div 8(2,3)-B(2,1) * B(1,3)) / 1$ FNOM

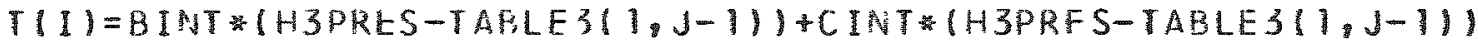

(H3PRES-TABLE $3(1, J-1))+$ TABLE $3(2, \mathrm{~J}-1)$

GO TO 52 
38 CONTINUE

GO TO 998

$40 T(I)=T A B L E 4(2, J)$

GO TO 52

$42 B(1,1)=$ TABLE $4(1, J)-$ TABLE $4(1, J-1)$

$B(1,2)=B(1, \|, B(1,1)$

$B(1,3)=$ TARLE4 $(2, J)-T A B L E 4(2, j-1)$

$B(2,1)=$ TARLE $4(1, J+1)-T A B L E 4(1, j-1)$

$B(2,2)=B(2,1) * B(2,1)$

$B(2,3)=T A B L E 4(2, j+1)-T A B L E 4(2, j-1)$

$C E N O M=B(1,1)=B(2,2)-B(2,1)=B(1,2)$

$B I N T=(B(1,3) * B(2,2)-B(2,3) * B(1,2) 1 / D E N O M$

$C I N T=(B \mid 1,1) * B(2,3)-B(2,1) * B(1,3)) / D E N O M$

$T(I)=B I N T$ (H4PRES-TABLE4 $(1, \mathrm{~J}-1)$ ) +CINT: (H4PRES-TABLE4 $(1, \mathrm{~J}-1)$ )

I: (H4PRES-TARLE4 $(1, \mathrm{~J}-1))+$ TABLE $4(2, \mathrm{~J}-1)$

$52 R(I)=$ (VOLT $R$ RTANR / CURR

$B E T A=-0.010$

RMSCEV $=99999999.0$

$55 \mathrm{~B}(1,1)=0.0$

$B(1.2)=0.0$

$\mathrm{B}(1.31=0.0$

$B(2,1)=0.0$

$B(2,2)=0.0$

$B(2.3)=0.0$

NOMAGN $=1$

DO $72 I=1$ NUMBER

IF (THERMIII) $63,72.63$

63 KINDI $=$ KIND $(1)$

NOMAGN $=2$

GO TO $(65,65.65,65,72) \cdot K I N D I$

65 XKAPPA $=1.0 /(T(I)+A L P H A / T(I)+B E T A)$

$B(1,1)=B(1,1)+1,0$

$B(1,2)=B(1,2)+X K A P P A$

$B(1,3)=B(1,3)+$ THERM (I)

$B(2,1)=B(1,2)$

$B(2,2)=B(2,2)+X K A P P A=X K A P P A$

$B(2,3)=8(2,3)+X K A P P A$ THER II

72 CONTINUE

GO TO 1219,741, NOMAGN

74 CENOM=B(1, 1$) \div B(2,2)-B(2,1)=B(1,2)$

THER:A $=(B(1,3)=B(2,2)-B(2,3)=B(1,2) / / D E N O M$

THERMB $=(B(1,1)=B(2,3)-B(2,1) B(1,3)) / D E N O M$

$P=0.0$

SDEV $=0.0$

DO $87 I=1$, NUMBER

IF (THERM (I) $80,86,80$

$80 \mathrm{KINDI}=\mathrm{KIND}(I)$

Go TO $(82,82,82,82,86), K$ NDI

82 DEV(I)=THERMA+THERMB / (T (I)+ALPHA/T(I)+BETA)-THERM (I)

SOEV $=$ SDEV +DEV(I) SDEV(I)

$P=P+1.0$

GO TO 87 


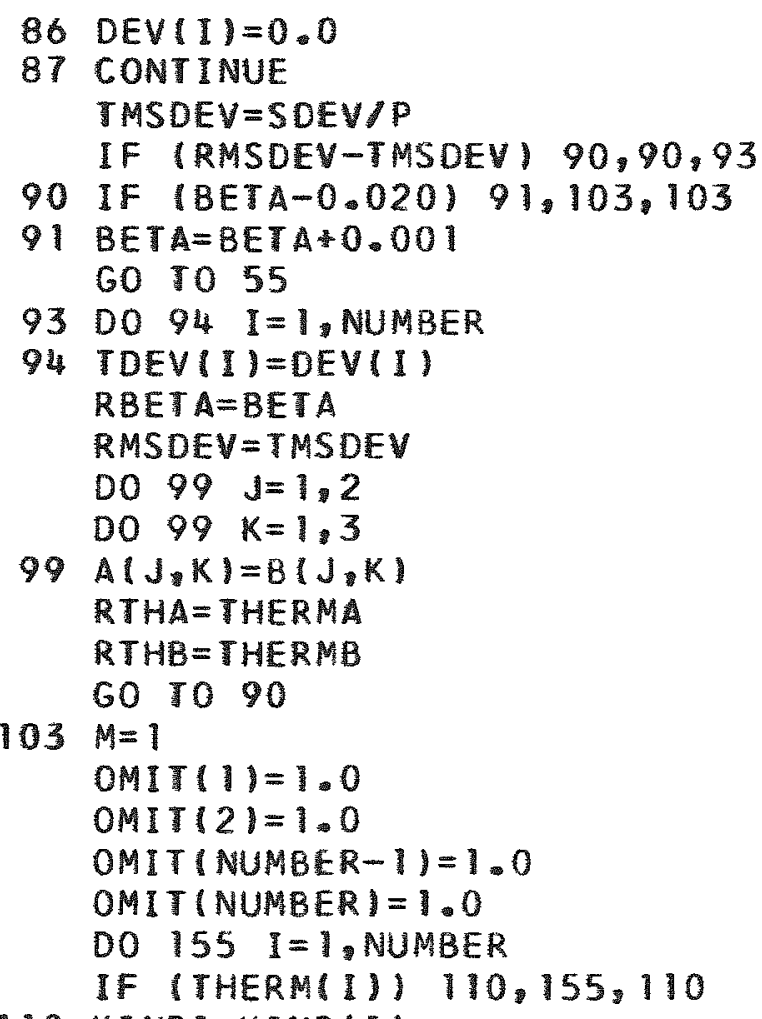

$110 \mathrm{KINDI}=\mathrm{KIND} I 1$

GO TO $(112,12,112,112,155$, KINDI

$112 \pi M I=0.0$

$M M 2=0.0$

$T P \|=10.0$

$T P 2=10.0$

DO $138 \quad J=1$, NUMBER

IF ITHERM(J) $18,138,118$

$118 K I N D J=K I N D(J)$

GO TO $(120,120,120,120,138), K I N D J$

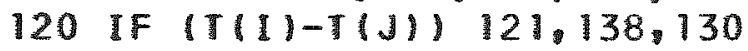

121 IF $(T(J)-T P 2) \quad 122,122,138$

122 IF $(T(J)-T P \| 125,125,123$

$123 \quad T P 2=T(d)$

$N P 2=J$

GO TO 138

$125 \mathrm{TP2}=\mathrm{TP} 1$

NP2 $=$ NP I

$T P \mid=T(J)$

$N P 1=\mathrm{J}$

GO TO 138

130 IF (TIN)TM2) 138, I3!, 13)

I3IIF IT(J)-TMI) 132,132,134

$132 \quad T M 2=T(J)$

NM2 $=J$

GO $1 0 \longdiv { 3 8 }$

$134 T M 2=T M 1$

NM2 $=$ NM1

$T M]=T(N)$

$N M I=\mathrm{J}$ 


\section{CONTINUE}

139 IF (TN2) $996,144,140$

140 IF $(T P 2-10.0) 141,144.995$

141 AVDEV = (TCEV (NM2) TDEV(NM2) + TDEV (NM) IDEV(NM) +TDEV (NPI) 1*TDEV(NP 1)+TOEV (NP2) TDEV(NP2)//4.0 $A B S M D=T D E V(I)$ TDEVII)

IF (ABSMD-9.0 AVDEV) $144,146,146$

144 ONIT(I) $=1.0$

GO TO 155

146 OMITI I I $=0.0$

$P=2$

XKAPPA $=1.0 /(T(1)+A L P H A / T(1)+R B E T A)$

$A(1,1)=A(1,1)-1.0$

$A(1,2)=A(1,2)-X K A P P A$

$A(2,1)=A(1,2)$

$A(2,2)=A(2,2)-X K A P P A=X K A P P A$

$A(1,3)=A(1,3)-$ THERM $(1)$

$A(2,3)=A(2,3)$-XKAPPA $T H E R M(1)$

155 CONTINUE

60 TO $(147,157)$,

157 DENCM $=A(1,1)=A(2,2)-A(2,1)=A(1,2)$

RTHA $=(A(1,3) * A(2,2)-A(2,3)$ A $(1,2) / / O E N O M$

$R T H B=(A(1,1) * A(2,3)-A(2,1) * A(1,3)) / D E N O M$

DO $156 \quad I=1$. NUMBER

IF (THERMII) $158,156,158$

$158 \mathrm{KINDI}=\mathrm{K} I \mathrm{ND}(1)$

GO TO $(159,159,159,159,156), K I N D I$

159 TDEV II) =RTHA+RTHB/(TII)+ALPHA/T(I)+RRETA)-THERM (I)

156 CONTINUE

147 IF ISENSE SWITCH 6) 160,148

148 PRINT 16I, (NAMEIII,I $=1,12)$

PRINT 163

PRIPIT 165, RTHA, RTHB, ALPHA, RBETA

PRINT 167

GO TO 168

160 WRITE DUTPUT TAPE 6,161, (NAME(I), I=1,12)

161 FORMAT (IHII2A6)

WRITE OUTPUT TAPE 6,163

163 FORMAT (/26H MAGVETIC THERMCMETER DATA)

WRITE DUTPUT TAPE 6,165, RTHA, RTHB,ALPHA,RBETA

165 FORMAT $1 / 5 \mathrm{H} A=$ F10.3.7H $B=F 10.4,11 \mathrm{H} \quad$ ALPHA $=$ F9.6.

NOH BETA $=F 8.41$

WRITE CUTPUT TAPE 6,167

167 FORMAT (/46H T (DEG K) R (OHMS) KAPPA K(F)-K(E)/120X)

168 ARG $(1)=0.0$

$\operatorname{ARG}(2)=0.0$

$\operatorname{ARG}(3)=0.0$

$A R G(4)=0.0$

DO $185 I=1$, NUNBER

IF (THERM(I)) 174, 185,174

$174 \mathrm{KINDI}=\mathrm{KINDQI})$

GO TO $(177,177,177,177,185), K I N D I$ 
177 IF (ABSF(TII))-ARG(1)) 179,179,178

178 ARG $11=A B S F(T\|I\|$

179 IF (ABSFIRII)-ARG(2)) 181, I81,180

180 ARG $(2)=A B S F(R(1))$

181 IF (ABSFITHERM(I) I-ARG 3$)$ ) $183,183,182$

182 ARG (3)=ABSFITHERMII)

183 IF (ABSF (TDEV(I))-ARG (4)) 185,185,184

184 ARG (4)=ABSF(TCEV(I))

185 CONTINUE

DO $195 \quad I=1.4$

SCALE III $=1.0$

IF (ARG(1)-1.0) 190,191.192

188 ARG (I) $=A R G(I) * 10.0$

SCALE II)= SCALE II $* 10.0$

190 IF (ARG(I)-0.1) 188.195.195

191 SCALEII $=$ SCALEII $/ 110.0$

$192 \mathrm{APG}(I)=A R G(1) / 10.0$

SCALE II) =SCALE(I//10.0

IF (ARG(I)-1.0) 195,192,192

195 CONTINUE

DO $211 I=1$. NUMEER

IF (THERMII) 198,211,198

198 KINCL = KINDII

GO TO $1199,199,199,199,2111$, KINDI

199 IF (SENSE SWITCH 6) 200,206

206 IF IOMITIII) 994.208 .207

207 PRINT 202,TII),R(I), THERM II),TDEVII), NCODEII)

SO TO 205

208 PRINT 204,TIIIRII).THERMII), TDEV(II, NCODE II)

$60 \quad 205$

200 IF IOMITIII $994,203,201$

201 WRITE OUTPUT TAPE 6,202, TII,RIII, THERMIII,TDEVIII, NCODEII)

202 FORMAT I1H F9.7,F13.5.F11.4,FI3.5.I121

GO TO 205

203 WRITE OUTPUT TAPE 6,204, T(I),R III THERM(I), TDEV II , NCODEII)

204 FORMAT IH F9.7.F13.5.F11.4,F13.5.I12.9H OMTT

205 PP $\|=T\| \div$ ICALE $\|$

$P P 2=R(I): S C A L E(2)$

PP $3=$ THERM (1) *SCALE(3)

PPU $=$ TDEV(I) SCALE(4)

IF ISENSE SWITCH 6) 209.212

212 PUNCH 213,PP1,PP4,PP2,PP3,OMITIII,NCODE II)

213 FORPAT (F10.7,F10.7,F10.7,F10.7,F10.1,110)

GO TO 211

209 WRITE OUTPUT TAPE 6,210,PP1,PP4,PP2,PP3,OMITIII,NCODEIII

210 FORMAT (1HOF1O.7,F10.7,F10.7,F10.7,F10.1,110)

211 CONTINUE

CALL DP $(20000)$

DO $217 \quad I=1$, NUUBER

KINDI $=$ KINO (I)

GO TO $(217,217,217,217,216), K I N D I$

216 TI I = (IRTHB-(THERM(I)-RTHA) -RBETA + SQRTF(IRTHB-(THERM(I) -RTHA)

I*RBETA) (RTHB-(THERM(I)-RTHA) BRETA -4.0 (THERM (I)-RTHA) ALPHA

2: (THERMIII-RTHA) //2.0 (THERMIII-RTHA) 
217 CONTINUE

CALL LVE

219 CALL CALIB(NU:BER)

IF ISENSE SWITCH b) 220.22 I

220 END FILE 6

221 STOP 77777

999 STOP Ol

998 STOP 02

996 STOP 04

995 STOP 05

394 STOP 06

ENO $10,1,0,0,11$ 
SURROUTINE CALIBINU"BERI

OIMEVSICN LSFN $(8), F(9), 2(100), T(100), A(8,9), B(9,9)$, CCEFC $(8)$,

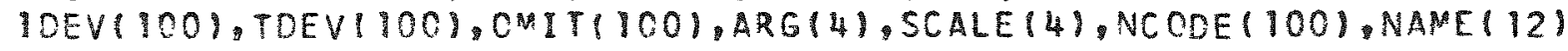

COWMON R,T, NAME, NCOCE, LSFN, F, COEFC

IF ISEVSE SHITCH 2) 219,218

2 ISEAD 220, NCCVST, (LSFN II), I=1, NCONST)

SO 10221

219 REAC INPUT TAPE 2,220, VCONST, (LSFNII), I= I, NCONST)

220 FORAAT II?,17, 14,17,14,16,15,15,151

221 CALL DP:20000

NCI $1=$ NCONST 1

DO $226 \quad I=1$, NCONST

DO $226 \quad J=1, \times C I$

226 E $(1, J)=0.0$

DO $304 L=1$, NUNBER

CALL LSQFN NCONST LI

$300 W=T(L)$

$F(N C 1)=1.0 / T(L)$

CO $304 \quad I=1$.NCONST

DO $304 \mathrm{~J}=1, \mathrm{NCl}$

$304 \mathrm{E}(I, J)=(I, J)+F(I)+F(J) \cdots$

$M=1$

366 CO $308 \quad 1=1$, NCONST

CO $308 \quad J=1$, VC

$308 \mathrm{~A}(\mathrm{I}, \mathrm{J})=0(1, \mathrm{~J})$

NCMI $=$ NCONST-1

ro $318 \mathrm{~K}=1$, Nen

$L=K+1$

CO $318 \quad I=L, N C O N S T$

If $(A \| I, K)) 314,318,314$

314 QUOT $=A(K, K) / A(1, K)$

CO $\$ 17 \mathrm{~J}=\mathrm{L}, \mathrm{NCO}$

$A(I, J)=A(I, J) * Q U O T-A(K, J)$

317 CONTINUE

318 CONTINUE

$J=N C$ CNST

$\operatorname{COEF}(J)=A(J, N C) / A(J, J)$

320 SIG०A $=0.0$

DC $322 I=J, N C O N S T$

322 SIGMA $=5$ IGNA+COEFC(I) $A(J-1, I)$

COEF $\left.(J-1)=(A \mid J-1,1 C 1)-5 I G^{M} A\right) / A(J-1, J-1)$

$\mathrm{J}=\mathrm{J}-1$

If $|\mathrm{J}-\| 1| 993,326,320$

326 CO $333 \quad 1=1$. NUMBER

CALL LSQFNINCONST, II

329 TCALC $=0.0$

DO $333 \mathrm{~J}=1$, NCONST

TCALC = TCALC+COEFC(J)*FIN

DEV(I) $=$ TCALC- $1.0 / T(1)$

333 TDEV (I) $=1.0 /$ TCALC-TII)

GO TC (335.364).

335 ONIT $(1)=1.0$

$O M I T(2)=1.0$

CMITINUNER -1$)=1.0$ 
OMITINUMBER $=1.0$

$N=2$

CO $360 \quad I=1$, NUPBR

$112 \quad T M 1=0.0$

$T^{M}=0.0$

$T P \|=10.0$

TP2 $=10.0$

DO $138 \mathrm{~J}=1$, NU $B E R$

120 IF $(T(I)-T(J)) 121,138,130$

121 IF $(F(J)-T P 2) \quad 122,122,138$

122 IF $(T(J)-T P I) 125,125,123$

$123 T P 2=T(J)$

NP2 $=\mathrm{J}$

GO TO 138

125 TP2 $=T P$ T

$N P 2=N P 1$

$T P \backslash=T(J)$

NP $=\mathrm{J}$

Go $10 \quad 38$

$\$ 30$ IF (T(J)-TM2) $138,131,131$

13! IF (TIJ)-TMI) $32,132,134$

$132 T M 2=T(J)$

NM2 $=\mathrm{J}$

GO TO 138

$134 T M 2=T M$

NM $2=\mathrm{NM}$

$T M I=T(J)$

$N M !=J$

138 CONTINUE

344 IF (TM2) $996,349,345$

345 IF ITP2-10.C) 346.349 .995

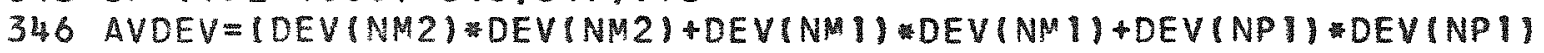
IDEV (NP2) DEVINP211/4.0

$\triangle B S M D=D E V(I) \times D E V(I)$

IF (APSMD-9.0 AVDEV) 349.351 .35 ।

349 OMITI 1 (I) $=1.0$

60 TO 360

35 OMIT(I) $=0.0$

$N=3$

CALL LSQFN (NCONST.II

$355 W=-T(\mathbb{I})$

F(NC) $)=1.0 / T(1)$

DO $359 \quad J=1$, NCONST

DO $359 \mathrm{~K}=1 . \mathrm{NCl}$

$359 B(J, K)=B(J, K)+F(J) \div F(K)=W$

360 CONTINUE

If $(\mathrm{N}-2) 993,364,362$

$362 \mu=2$

60 TO 306

364 CALL LVE

IF ISENSE SWITCH 6) 366,365

365 PRINT 367, (NAME (I), $I=1,12)$ 
PRINT 368

PRIVT $370,(1$ COEFCII), LSFNII), $I=1$, NCONST)

PRINT 372

CO TO 373

366 WRITE OUTPUT TAPE 6,367 . (NAME (1), I $=1,121$

367 FORMAT (IH\|12A6)

WRITE OUTPUT TAPE 6.368

368 FORMAT (/35H TEMPERATURE CALIBRATION CURVE CATA/120X)

WRITE OUTPUT TAPE $6,370,($ (CCEFC (I), LSFN(I)), $I=1$, NCONST)

370 FORMAT | 1 H E $15.8,17$ )

WRITE OUTPUT TAPE 6,372

372 FORNAT (/5 IH T (DEG K)

$1 / 120 \times 1$

$R$ (OHMS) $\quad / T(F)-1 / T(E) \quad T(F)-T(E)$

373 ARG $11=0.0$

$A R G(2)=0.0$

$A R G(3)=0 . C$

$A R G(4)=0.0$

DO $386 \quad I=1$, UMBER

IF (ARSFITIIU-ARGI\| $380,380,37 \%$

379 ARG 1$)=A B S F(T(I))$

380 IF (APSFIRII)-ARG $(2 \| 382,382.381$

38 IRG $(2)=A B S F(R(1))$

382 IF (ABSFITCEV(I)-ARG(3)) $384 \cdot 384 \cdot 383$

383 ARG (3)=ABSF(TDEV (I)

384 IF (ABSF(DEV(I))-ARG(4)) $386,386.385$

385 ARG $(4)=A B S F(D E V(I))$

386 CONTINUE

DO $397 \quad I=1,4$

SCALE I $=1.0$

IF (ARGII)-1.0) $392,393,394$

390 ARGIII=ARG (I) 10.0

SCALE I $)=S C A L E(I)=10.0$

392 IF (ARGII)-0.1) 390.397 .397

393 SCALE II) = SCALE II/10.0

394 ARG III =APGII1/10.0

SCALE IT) = SCALE(I/10.0

397 CONTINUE

IF (ARG(I)-1.0) $397,394.394$

DO $411 I=1$. NUMBER

IF (SENSE SWITCH 6) 399.398

398 IF (OMITIII) 992.407 .406

406 PRINT $401, T(1), R(1), D E V(I), T D E V I I), N C O D E(I)$

GO 10405

407 PRINT 404, TII, RII), DEV(I), TDEV(I), NCODEII)

60 ro 405

399 IF (OMITII) $992,403,400$

400 WRITE OUTPUT TAPE $6,401, T(I), R I I), D E V I I 1, T D E V(11$, NCODE II)

401 FORMAT IIH FQ.7,F13.5,F15.8,F13.8, II)

60 TO 405

403 hRITE OUTPUT TAPE 6,404,T(I),R(I),DEVII),TDEVII),NCODEIII

404 FORMAT IIH F9.7.F13.5,F15.8,F13.8, 12,9H

OMITI

$405 \mathrm{PP} 1=T(1) \times$ SCALEII)

$P P 2=R(1)=S C A L E(2)$

$P P 3=$ TDEV (1) 3 SALE (3) 


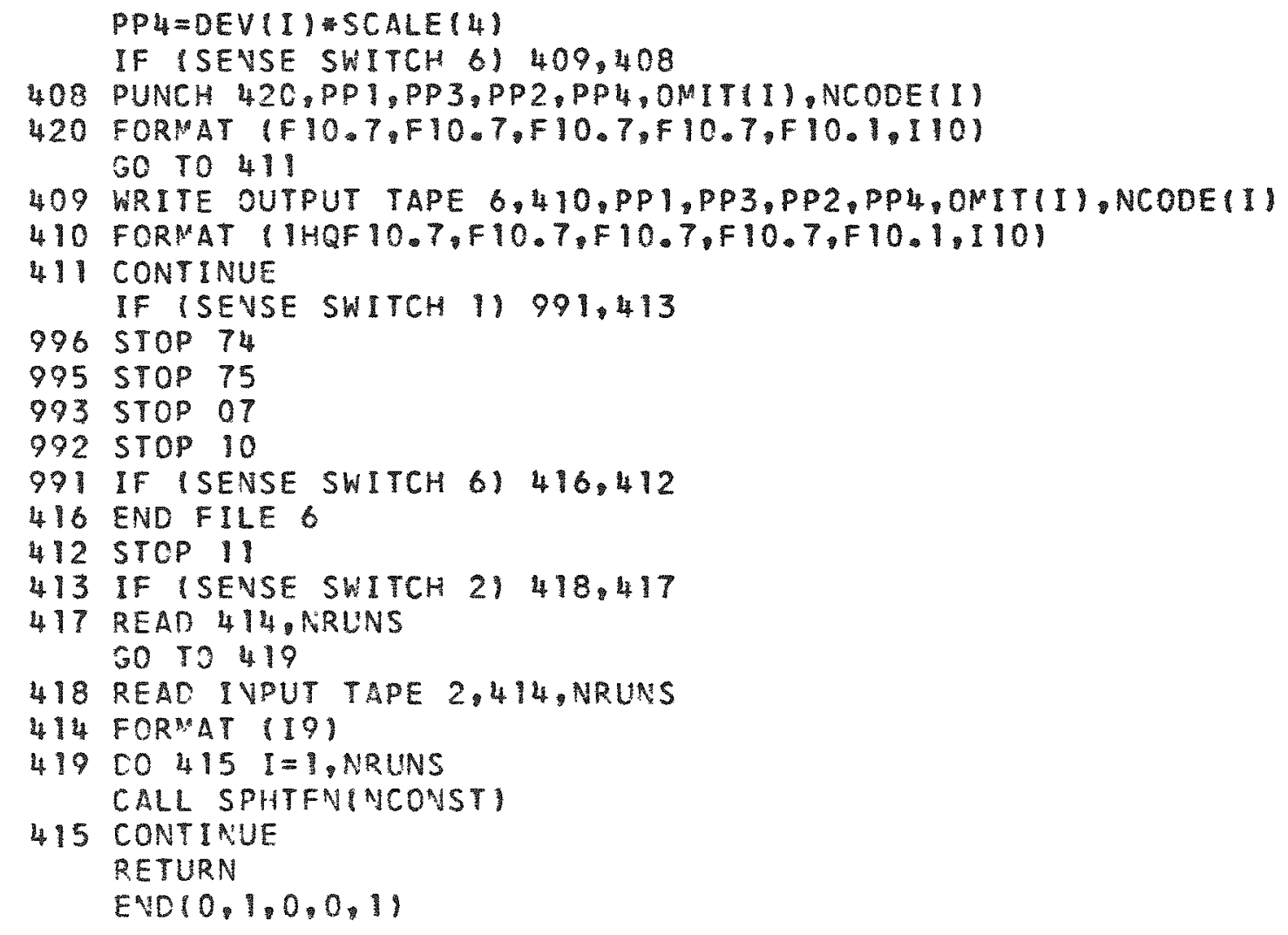


SUBROUTINE SPHTFNINCONSTI

DIMENSION EDRIFT(12), DTIMEH(12), DTIMEM (12),DTIMES $(12)$,DEV(12), INCODE (200), COEFC(8), F(8), ARG (2), SCALE(2), CP(200), T(199), DELTAT $2(200)$, NDUMMY $(100)$, NAME(12),R(1),LSFNI8)

COMMON R,T, NAME, NDUMMY,LSFN,F, COEFC

IF ISENSE SWITCH 21414,413

413 READ 415, NLOOP

READ $417, H R E S A, H R E S B, R S T A N H, R S T A N R, C A L A, C A L B, X M O L E S$

GO TO 418

414 READ INPUT TAPE 2.415. NLOOP

415 FORMAT 1191

READ IVPUT TAPE 2, 17, HRESA,HRESB,RSTANH, RSTANR, CALA, CALB, XMOLES

417 FORMAT IF9.3,F11.4,F11.2,F $11.2, F 10.4, F 10.4, F 10.6$ )

$418 \quad L V E D=1$

419 RAK $=1.0$

$R B K=0.0$

$R C K=0.0$

$R D K=0.0$

REK $=0.0$

RFK $=0.0$

IF ISENSE SWITCH 2 ) 425.424

424 REAC 426 .NDRIFT, (EDRIFT(I), DIIMEHII),DTIMEM(I),DTIMESII).

$I I=I . N D R$ IFTI

60 TO 427

425 READ INPUT TAPE 2,426, NDRIFT. (EDRIFTII),DTIMEHII),DTIMEMII) IDTINESIII, $=1$, NDRIFT)

426 FORMAT II9,FI1.2,F5.0,F3.0,F3.0,FI1.2,F4.0,F3.0,F3.0,F10.2,F4.0,

$1 F 3.0, F 3.0,31 / F 20,2, F 5.0, F 3.0, F 3.0, F 11.2, F 4,0, F 3.0, F 3.0, F 10.2$.

$2 F 4.0, F 3.0, F 3.011$

427 DO $428 \quad I=1$. NDRIFT

428 DTIMESII) $=$ DTIMES $(1)+60.0$ D (DTIMEM $(I)+60.0 \% 0 T$ TMEHII)

DO $435 \quad I=2$ NDRIFT

$R A K=R A K+1.0$

RBK $=R B K+D T I M E S(I)-D T I M E S I)$

$R C K=R B K$

RDK=RDK+IDTIMES II)-DTIMES (U) -DTIMES II)-DTIMESIII

$R E K=R E K+E D R I F T(I)-E D R I F T(1)$

$435 R F K=R F K+(E D R I F T \| I)-E D R I F T(\|)$ (DTIMES(I)-DTIMES $1 \|$

$D E N O M=R A K=R D K-R C K=R B K$

$Y O 2=(R A K=R F K-R C K * R E K) / C E N O M$

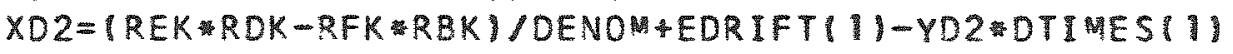

SDEV $=0.0$

DO $442 I=1$, NDRIFT

DEV II) $=X D 2+Y D 2$ DIIMES III-EDRIFTII

442 SDEV $=$ SDEV $+D E V(I) * D E V(I)$

$D N B R=N D R I F T$

SDEV $=$ SDEV $/ D N B R$

GO TO (445.467).LVED

445 IF ISEVSE SWITCH 6 ) 446.444

444 PRINT 447 , (NAMEII), I=1, 12)

PRINT 448

PRINT 450

PRINT 452, SCEV

PUNCH 460 . (NAME II I, I $=1,12$ ) 
460 FORMAT $(1246)$

SO TO 453

446 WRITE SUTPUT TAPE $6,447,($ NAME (I), $[=1,12)$

447 FORMAT (IHII2A6)

WRITE SUTPUT TAPE 6,449, (NAMEII), I $=1,12$ )

449 FORMAT (IHQ12A6)

WRITE DUTPUT TAPE 6.448

448 FOR MAT (/33H UNCORRECTED SPECIFIC HEAT OUTPUT)

WRITE OUTPUT TAPE 6.450

450 FORMAT (/51H C (MJ) T IDEG K) DELTAT

$(/ 120 \times)$

WRITE OUTPUT TAPE $6.452 .50 E V$

452 FCRMAT $(37 X, F 14.31$

453 LVEHTG $=1$

$K=0$

456 IF ISEVSE SWITCH 2) 454,457

457 READ 455, RESI2,TRESIH.TRESIM.TRESIS,BTIMEH, RTIMEM,BIIMES, EHTG2, IHTIMES HTIMEF, NCODE (K+1) GO TO 458

454 READ INPUT TAPE 2,455, RESI2,TRESIH,TRESIM,TRESIS,BTIMEH, BTIMEM, 1BTIMES, EHTG2, HTIMES,HTIMEF, NCODE (K+1)

455 FOR

458 RESI2=RESI2/RSTAVR

TRESI $2=$ TRESIS $+60.0 *$ (TRESIM+60.0\%TRESIH)

BTIME2 = BTIMES+60.0. (BTIMEM+60.0*BIIMEH)

HTINE2 = HTIMES+HTIMEF/60.0

EHTG2=EHTG2/RSTANH

GO TO (462,474), LVEHTG

462 ARG $(1)=0.0$

$A R G(2)=0.0$

DO $509 K=1$. NLOOP

$Y D 1=Y D 2$

$X D I=X D 2$

LVEC $=2$

GO TO 419

467 RESII=RESI2

TRESI $1=$ TRESI2

BTIMEI=BTIME2

EHTOI=EHTG2

HTINEI =HTIME2

LVEHTG $=2$

SO TO 456

474 ERESI $1=X D$ I+YD I TRESII

ERESI $2=X D 2+Y D ? * T R E S I 2$

TINEAN = BTIMEI +HTIMEI/2.0

EXTEI $=X D 1+Y C$ I TIMEAN

EXTE2 $=X 02+Y C 2 * T 1 M E A N$

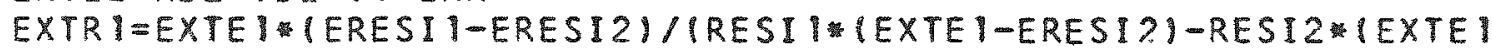

1 -ERESIII

EXTR2=EXIE2*1ERESII-ERESI2)/(RESII*IEXTE2-ERESI?)-RESI2* (EXTE2

|-ERESIII)

CALL CP 120000$)$ 
$R(1)=E \times T R$ I

CALL LSQFNINCONST.1)

CALL LVE

485 TEMP $1=0.0$

DO $487 \mathrm{~J}=1$, NCONST

487 TEMPI = TEMP $1+C O E F C(J) * F(J)$

TEMPI $=1.0 /$ TEMPI

CALL DP (20000)

$R(1)=E X T R 2$

CALL LSQFNINCONST, II

CALL LVE

491 TEMP2 $=0.0$

CO $493 \mathrm{~J}=1$, NCONST

493 TEMP $2=$ TEMP2 $+C O E F C(J) \div F(J)$

TEMP2 $=1.0 /$ TENP2

$T(K)=(T E M P 1+T E M P 2) / 2.0$

$C P C A L=(C A L A T(K) T(K)+C A L B)=T(K)$

CELTAT $(K)=$ TEMP2-TEMP

RESHTR = HRESA +HRESB $T(K)$

CP $(K)=$ IEHTG \#EHTG I RESHTR HTIME I/DELTAT(K) 1000.0-CPCAL//XMOLES

IF (SENSE SWITCH 6) 501.500

500 PRINT 502, CP(K), T(K), DELTATIK), SDEV,NCODE(K)

60 TO 503

501 WRITE OUTPUT TAPE $6,502,6 P(K), T(K), D E L T A T(K), S D E V, N C O D E(K)$

502 FORMAT IIH FI0.5,F13.8,F13.8,FI4.3,1121

503 IF (ABSF(CP(K))-ARG 1$)$ ) 505.505 .504

$504 \quad A R G(\|)=A B S F(C P(K))$

505 IF (ABSF(TIK))-ARG(2)) 509.509 .506

506 ARG $(2)=A B S F(T(K))$

509 CONTINUE

DO $520 \quad I=1.2$

SCALEIII $=1.0$

IF (ARG (1)-1.0) 515.516 .517

$513 \triangle A R(I)=A R G(I) * 10.0$

SCALE(I) $=$ SCALE(I) 10.0

515 IF (ARGII)-0.11 $513.520,520$

516 SCALE II $=$ SCALEII//10.0

517 ARGII) =ARG(I//10.0

SCALE(I) = SCALE(I)/10.0

IF (ARG (1)-1.0) 520.517 .517

520 CONTINUE

DO $526 \mathrm{~K}=1$, NLOOP

$P P \mid=C P(K)=S C A L E(1)$

$P P 2=T(K) \div S(A L E(2)$

IF (SENSE SWITCH 6) 524.523

523 PUNCH 527, PP $2, P P 1, C P(K), T(K), D E L T A T(K), N C O D E(K)$

527 FORMA (F10.7,F10.7,F10.5,F10.7,F10.7,110)

60 TO 526

524 WRITE OUTPUT TAPE 6,525,PP2,PP1,CP(K),TIK),DELTAT(K),NCODE(K)

525 FORMAT IIHQF 10.7,F10.7,F10.5,F10.7,F10.7,1101

526 CONTINUE

RETURN

END $10,1,0,0,11$ 
SUBROUTINE LSQFN (NCONST,L)

DIMENSION R(100), T(100), VCODE $(100), L S F N(8), F(8), C O E F C(8)$, NAME(I2) COMMON R, T, NAME, NCODE, LSFN, F, COEFC

229 DO $298 \quad I=I, N C O N S T$

LSFNI $=$ LSFN II

Go TO $1232,234,236,238,240,242,244,246,248,250,252,254,256,258$, $1260,262,264,266,268,270,272,274,276,278,280,282,284,286,288,290$. $2292,294,2961$. LSFNI

$232 F(L)=1.0 / 1 R(L) \div R(L)=R(L)=R(L) * R(L))$

GO TO 298

$234 F(I)=1.0 /(R(L) * R(L) \div R(L) \div R(L))$

GO TO 298

$236 F(I)=1.0 /(R(L)=R(L) \div R(L))$

GO TO 298

$238 F(I)=1.0 /(R(L) R(L)=S Q R T F(R(L))$

GO TO 298

$240 F(I)=1.0 /(R(L)=R(L))$

GO TO 298

$242 F(I)=1.0 / 1 R(L) * S Q R T F(R(L) 1)$

60 TO 298

$244 F(I)=1.0 / R(L)$

GO TO 298

$246 F(I)=1.0 / S Q R T F(R(L))$

GO TO 298

$248 F(I)=1.0$

GO TO 298

$250 F(I)=S Q R T F(R(L)$

GO TO 298

$252 \mathrm{~F}(1)=\mathrm{R}(\mathrm{L})$

GO TO 298

254. $F(I)=R(L) * S Q R T F(R(L))$

GO TO 298

$256 F(L)=R \| L) R \| L\}$

GO TO 298

$258 F(I)=R(L)=R(L)=S Q R T F(R(L))$

GO $T 0298$

$260 \mathrm{~F}(I)=R(L)=R(L) R(L)$

GO TO 298

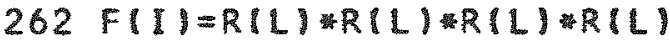

60 TO 298

$264 F(I)=R(L)=R(L)=R(L)$ RIL)

GO TO 298

$266 \mathrm{~F}(1)=1.0 / \mathrm{EXPF}(\mathrm{R}(\mathrm{L} / / 2.01$

60 TO 298

$268 F(I)=1.0 / E X P F(R(L)$

Go ro 298

$270 \mathrm{~F}(\mathrm{I})=1.0 / \mathrm{EXPF}(2.0 \mathrm{R}(\mathrm{L})$

60 T0 298

$272 \mathrm{~F}(1)=1.0 / E X P F(3.0$ M $R(L))$

60 TO 298

$274 \mathrm{~F}(\mathrm{I})=\mathrm{EXPF}(\mathrm{R}(\mathrm{L} / / 2.0)$

GO TO 298 


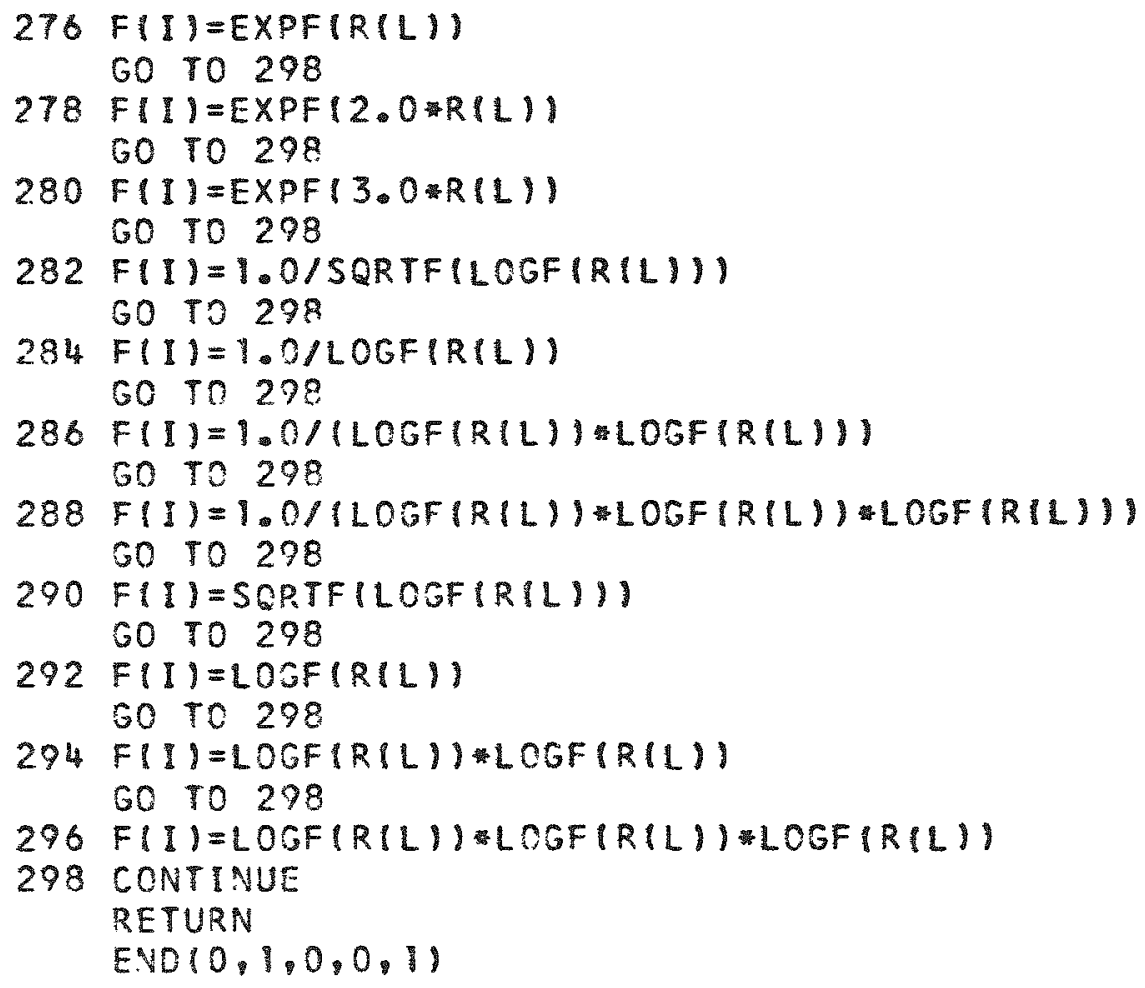


PAT ROACH CURVATURE CORRECTION PROGRAM

DIMEVSICNT(200), CP(200),DT(200), NCODE (200),DEV(200),OMIT(200). XNAME (12), ARG (3), SCALE (3),AIT, 15), B (7, 15), VCOEFS (7), CCOEFS (T). XCOEFW (7, 15), STDIT), CPFN (8), PVAR (T), PEONSTIT)

IFISENSESWITCH2) 2,1

I READ3, (NAME (I) I $=1,12$ )

READ5, NUMEER, NVAR, NCONST

READT, $(C P(I), T(1), D T(I), N C O D E(I), I=1, N U M B E R)$

READ , (PVAR I I), I = I, NVAR)

READII, (PCONST(I), $1=1$, NCONST)

REAC $13,($ CCOEFS (I), $I=1$, NCONST)

GOTO14

2 READINPUTTAPE 2, 3, (VAMEII , I $=1,12$ )

3 FORMAT 12 12A $\}$

READINPUTTAPE? 5 , NUMBER, VVAR NCONST

5 FORMATII9, III.III)

READINPUTTAPE $2,7,1$ (CP (I), T(I),DT(I), NCODE (I), I=1, NUMBER)

7 FORMATI $20 \times F 10.5, F 10.7, F 10.8,1101$

READINPUTTAPE2, 9 (PVAR $(1), 1=1$, VVAR)

9 FORMATIFQ.1.3IFI1.11.3IFIC.111

READINPUTTAPE2, 11, (PCONST $11,1=1$, NCONST)

1) FORMATIFQ.1.3IFI1.1),3(F10.1))

REACINPUTTAPE2, $13,($ CCOEFS $(I), I=1$, NCCNST)

13 FCRMATIF9.6.3(F)1.6), 3(F10.6))

14 CALLEP 120000 !

DO $171=1.7$

$0017 J=1.15$

$17 A(I, J)=0.0$

NVP $1=N Y A R+1$

CO33I $=1$, NUMBER

TTWO $=T(I)+D T(I) / 2.0$

TONE $=T(I)-C T(I) / 2.0$

$D 023 \mathrm{~J}=1$. NVAR

$P=P$ VAR $(J)+1.0$

23 CPFN $(J)=$ (PWR ITTWO,P)-PWR (TONE,P) //P (TTWO-TCNE )

SUMC $=0.0$

CO27J=1, NCOAST

$P=$ PCONST $J I+1.0$

27 SUMC = SUPC +CCOEFS $(J)$ (PWR $(T T W O, P)-P W R(T O N E, P) / / P$ QTTWO-TONE) CPFN $(N \cup P Y)=C P(I)-S U M C$

CPII $=E P F N(N V P \|)$

LVECPN= 1

$\operatorname{COS} 3 \mathrm{~J}=1$. NVAR

DOS3K $=1$. NYP 1

$33 A(J, K)=A(J, K)+C P F V(J) C P F U(K)$

NVPNV $=$ UVP I + IiVAR

CO39I = I. NVAR

NDUPB $Y=V Y P I+I$

A(I. NOUMMY) $=1.0$

$[039 \mathrm{~J}=1$. NVPAV

$39 B(I, J)=A \mid I, J)$

NVM $1=$ RVAR -1 


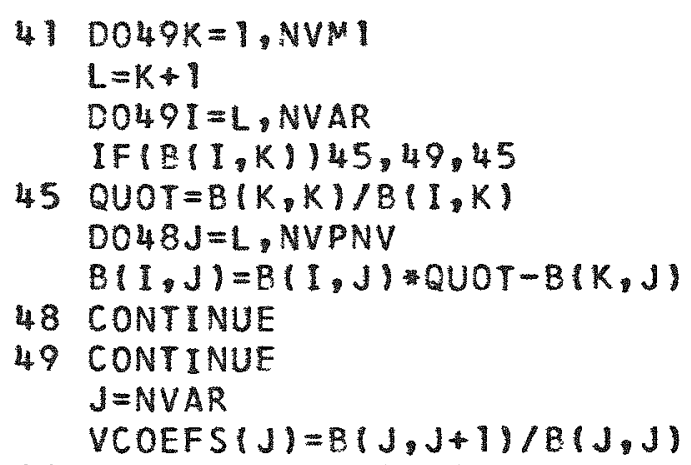

51 IF $(J-1) 986.58 .52$

52 SIGMA $=0.0$ D054I $=\mathrm{J}$, NVAR

54 SIGMA $=S I G M A+V C O E F S(I) \div B(J-1,1)$

VCOEFS $(J-1)=(B(J-1, N V P \|-S I G A) / B(J-1, J-1)$

$J=J-1$

G0T051

58 DO691 $=1$, NUMBER

TTWO $=T(I)+D T(I) / 2.0$

TONE $=T(I)-D T(I) / 2.0$

SUMV $=0.0$

$D 064 \mathrm{~J}=1$, NVAR

$P=P V A R(J)+1.0$

64 SUMV = SUMV+VCOEFS (J) * (PWR (TTWO,P)-PWR ITONE,P) / (P $(T T W O-T O N E)$ )

69 DEV (I) $=$ SUMV-CP(II)

GOTO $(71,100)$, LVECPM

71 OMIT $(1)=1.0$

OMIT $(2)=1.0$

OMITINUMBER-11=1.0

OMITINUMBER $)=1.0$

$\mathrm{N}=0$

D093I $=1$, NUMBER

$112 T M 1=0.0$

$T M 2=0.0$

$T P \mid=10.0$

$T P 2=10.0$

DO $138 \mathrm{~J}=1$, NUNBER

120 IF $(T(I)-T(J)\} 121,138,130$

121 IFITIJI-TP2) 122,122,138

122 IF(T $(J)-T P \|) 125,125,123$

$123 T P 2=T(J)$

NP2 $=J$

GO TO 138

125 TP2 $=$ TP I

$N P 2=N P 1$

$|P|=T|J|$

$N P I=J$

Goto 139

130 IF(TIJ)-TM2) 138.131.131

131 I $F(T(J)-T M \|) 132,132,134$

$132 T M 2=T(J)$

NM2 $=J$

GO TO 138 
$134 T M 2=T M 1$

$\mathrm{NM} 2=\mathrm{NM}$

$T M I=T(\mathrm{~J})$

NMI $=J$

138 CONTINUE

IFITM21996,81,77

77 IFITP2-10.0)78.81.995

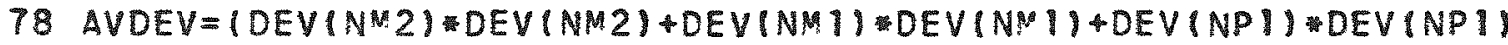
$1+D E V(N P 2)$ DEVINP21//4.0

$A B S M D=D E V(I)=D E V$ II

IF (ABSMD-9.0*AVDEV) $81,83,83$

8) OMIT(I) $=1.0$

G0T083

83 OMITI $I)=0.0$

$N=1$

TTWO $=T(I)+D T(I) / 2.0$

TONE $=T(I)-D T(I) / 2.0$

DO88J $=1$, NVAR

$P=P$ PAR $(J)+1.0$

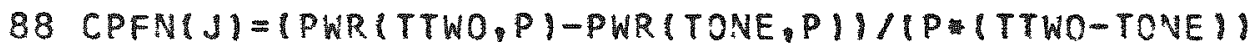

CPFN (NVPU $=C P \ I)$

DO92J $=1$, NVAR

DO92K = I, NVP I

$92 A(J, K)=A(J, K J-C P F N(J) C P F N(K)$

93 CONTINUE

IFIN1985, 100,95

95 LVECPM $=2$

DO981 =1. VVAR

DOQPJ $=1$, NVPNV

$98 B(I, J)=A(1, J)$

$60 \mathrm{TO}^{1}$

100 NVP2 $=$ NVAR +2

DO $109 \mathrm{~J}=$ NVP2, NVPNV

$K=N \cup A R$

COEFW $(K, J)=Q(K, J) / B(K, K)$

102 IF $(K+N V P I-J) 984,109,103$

103 SIG $A=0.0$

DO105I $=K$, NVAR

105 SIGNA=SIGMA+COEFW(I, J) BB(K-1,I)

COEFW $(K-1, J)=(B(K-1, J)-S(G M A) / B(K-1, K-1)$

$K=K-1$

Gorolo2

109 CONTINUE

SUMAONO $=0.0$

SUMV $2=0 . \mathrm{C}$

CO144I 1 , NUNEER

IFIONITIII1983,144,142

$142 S U^{M} V 2=S U^{*} V 2+C[V(I) \div D E V(I)$

SUMNO $=S U M N O+1.0$

144 CONTINUE

ENNC $=$ NYAR

SUMNO = SUMNO-FANO 
DO149I $=1$, NVAR

NDUMMY $=I+N Y P I$

149 STD (I) = SQRTF (SUMV2:ABSF(COEFW(I. NDUMMY) / /SUMNO)

CALLLVE

IFISENSESWITCHO)151,150

150 PRINT 152, (NAMEII), I $=1,12$ )

PRINT 154

PRINT156

PRINT 158

PRINT 160, (PVAR(I), I =1, NVAR)

PRINI16?

PRINT 164, (VCOEFS(1), I=1, VVAR)

PRINT166

PRINT 168, (STD (1), I = I, NVAR)

PRINTITO

PRINT 172, (PCONSTII), I=1, NCONST)

PRINTIT4

PRINT 176, ICCOEFS II, I $=1$, VCONST)

PRINT178

GOTO179

151 WRITEOUTPUTTAPE6, 152 , (VANE(I), I =1, 12)

152 FORMAT $(1 H 112 A 6)$

WRITEOUTPUTTAPE6, 154

154 FORMAT//31H CORRECTED SPECIFIC HEAT OUTPUTI

WRITEOUTPUTTAPE6, 156

156 FORMAT// $30 \times 2$ IHVARIABLE COEFFICIENTS

WR ITEOUTPUTTAPEB, 158

158 FORMAT / $35 \times 1$ IHPOWERS OF T)

WRITEDUTPUTTAPE6, 160, (PVAR (I), I $=1$, NVAR)

160 FOR UATI/1H TF15.8)

WRITEOUTPUTTAPE6, 162

162 FOR AT (/34X12HCOEFFICIENTS)

WRITEOUTPUTTAPEO, $164,($ VEOEFS (I), I $=1$, NVAR)

164 FORMATI/1H TF15.8)

WRITECUTPUTTAPEG, 166

166 FORMATI/31X19HSTANDARD CEVIATIONSI

WRITEOUTPUTTAPE6, $168,(5 T 0(1), 1=1$, NVAR)

168 FOR"AT / IH TFI5.8)

WRITEOUTPUTTAPE6, 170

170 FCRMAT///30X21HCONSTANT EOEFFICIENTS//35X/1HPOWERS CF T)

WR ITEOUTPUTTAPEB, 172, (PCONSTII), I=1, NCONST)

172 FORMAT (/ IH TF 15.8)

WRITEOUTPUTTAPEB, 174

174 FOR AT (/34X12HCEEFFICIENTS)

WRITEOUTPUTTAPEG, $176,($ CCOEFSII), $1=1$, NCCNST)

176 FORMATI/1H TF 15.8)

WRITEOUTPUTTAPEG, 178

178 FORMAT(//5UH C (MJ) TIDEGK) DELTA T C(FI-CIEI

$(/ 120 \times)$

179 ARG $(1)=0.0$

$A R G(2)=0 \cdot C$

$A R G(3)=0.0$

DO204I 1 1, NUMEER

CALLCP $\{20000\}$ 
SURV $=0.0$

COI86J $=1$, NVAR

188 SUMV = SUMV+VCOEFS (J) PWR ITII) PVAR UMI

SUn $C=0.0$

DO $199 \mathrm{~J}=1, \mathrm{NCO} S \mathrm{ST}$

189 SUMC $=$ SUMC+CCOEFS $(J) \div P$ WR (TII).PCONST (J))

$C P(I)=S U N V+S U M C-D E V(I)$

CALLLVE

IFISENSESWITCH6) 192,190

190 IFIOMITIII) $982,189,187$

I8T PRINT194,CP(I),T(I),DTII),DEV(I), NCODE(I)

GOTO198

188 PRINT 197,CP(I),TII),DTII),DEVII),NCODE(I) GOTC199

192 IFIOMITIII193?.196.193

193 WRITEOUTPUTTADE6, 194, CP(I), T(I), DT(I), DEV (I), NCODE(I)

194 FORMATIH F10.5,F13.8,F13.8,F14.7,1121

GOTO 198

196 WRITECUTPUTTAPEG, 197, CPII), TII),DTII), DEVIII,NCODEIII

197 FORMATIIH F10.5,F13.9,F13.8,F14.7,112,9H OMIT)

198 IFIAESF(CP(I))-ARSI $11200,200,199$

199 ARG 11$)=A B S F(C P(1))$

200 IF(ABSF(TII) $-A R G(2) 1202,202,201$

$201 A R G(2)=A B S F(T(I))$

202 IFIABSFIDEVII $1-A R G(3) 12 C 4,204.203$

203 ARG (3)=ABSF (DEV (I))

204 CONTINUE

$002151=1.3$

SCALE $(I)=\square . C$

IFIARG(I)-1.01210.211.212

208 ARGII $=A R G(I)=10.0$

SCALE II $=\$ C A L E(I)=10.0$

210 IF(ARG (I) -0.11208 .215 .215$

211 SCALE II $=S C A L E \| I / / 10.0$

212 ARGII $=A R G(1) / 10.0$

SCALE (I) $=$ SCALE (I)/10.0

IF(ARG (I) $-1.01215,212,212$

215 CONTISUE

CO2221 = 1. NUMPER

$P P \mid=C P(1)=S C A L E(\|)$

$P P 2=T(I) * S C A L E(2)$

$P P 3=D E V(I)$ \&CALE (3)

IFISENSESWITCHO) 220,210

219 PUNCH225,PP2, PP 1, PP3,OMITIII,NEODEIII

221 FORMAT I IHEF10.7,F10.7,F10.7,10XF10.1,1101 SOTC222

220 WRITEQUTPUTTAPE6, 221,PP 2,PP 1,PP 3,OMITIII,NCODE II

225 FORMATIF10.7,F10.7,F10.7, 10X,FIO.1,110I

222 CONTINUF

IFISENSESWITCHGI223,224

223 ENDFILES

224 STOP 77777 
$9965 T 0 P 64$

995 \$TOP65

986 5TOP16

985 STCP 17

984 STOP20

983 STOP21

982 STOP 22

ENC $10,1,0,0,11$ 
FUNCTIONPWRIT,PI SOTO13

IIFIP $+5.0122,24,2$

2 IF $(P+4.5) 22,26,22$

3 IFIP $=4.011,20,5$

$4 \quad$ IF $(P+3.5) 22,30.22$

5 IF $(P+3.0) 4,32,6$

6 IF $(P+2.5) 122,34,22$

7 IF $P(P+2.013,36,10$

8 IF $(P+1.5) 22,38,22$

9 IF $(P+1.0) 8.40 .22$

$10 \quad I F(P+0.5) 7,42,11$

1) IF(P) $22,44,12$

12 IF $(P-0.5) 22,46,22$

13 IF (P-1.017,48,17

14 IF $(P-1.5) 22,50,15$

15 IF $(P-2.0122 .52,16$

16 IF (P-2.5) $22,54,22$

17 IF (P-3.0)14,56.21

18 IF $(P-3.5) 22,59,22$

19 IF $(P-4,0) 18,60,20$

20 If $(P-4.5) 22,62,22$

21 IF $(P-5.0) 19.64,22$

$22 P W R=T$ 需 $P$ GOTC65

$24 P W R=1.0 /(T * T * T * T * T)$ GOT065

$26 \mathrm{PWR}=1.0 / 1 \mathrm{~T}$ T T T T SQRTFIT) GOTC65

$28 P W R=1.0 /(T * T * T * T)$ Gorcs 5

30 PWR =1.0/ IT T T SQRTFITI) SOTC65

$32 P W R=1.0 /(T$ T T $T$ ) GOTC65

$34 P W R=1.0 /(T * T * S C R T F(T))$ GOTC65

$36 P W R=1.01(T \mathrm{~T} T)$ GOTO65

38 PWR $=1.0 / 1 T * S Q R T F(T)$ SOT065

$40 \quad P W R=1.0 / T$ GOTC65

42 PWR $=1.0 / S G R T F(T)$ GOTO65

$44 P W R=1.0$ COTC65

$46 P W R=S G R T F(T)$ COTO65

$48 \quad P W R=T$ GoT065

$50 \quad P W R=T$ T $S Q R T F(T)$ 
601065

52 PWR $=T \cdot T$

Gor065

54 PWR = T T SERTF(T)

SOTO65

56 PWR $=T$ * T*T

G0T065

58 PWR $=T$ T T T SQRTF IT

SOT065

60 PWR $=T * T * T * T$

GOTC65

$62 P W R=T * T * T * T * S Q R T F(T)$

GoTro 5

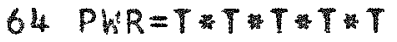

65 RETURA:

END $0,1,0,0,11$ 